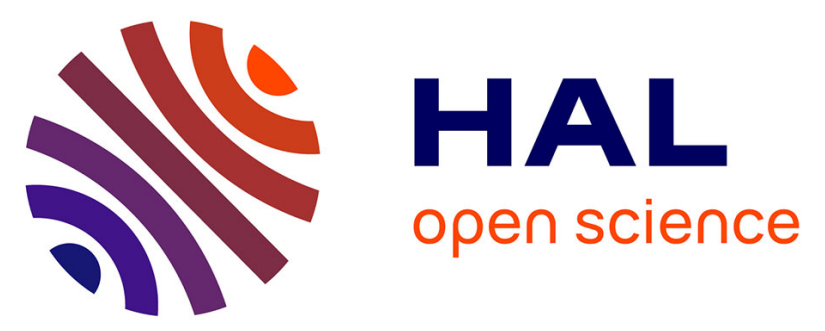

\title{
L'Aspre del Paradis à Corneilla-del-Vercol (Pyrénées-Orientales) : contribution à l'étude du Néolithique ancien et final roussillonnais
}

Claire Manen, Jean-Denis Vigne, Denis Loirat, Laurent Bouby

\section{- To cite this version:}

Claire Manen, Jean-Denis Vigne, Denis Loirat, Laurent Bouby. L'Aspre del Paradis à Corneilladel-Vercol (Pyrénées-Orientales) : contribution à l'étude du Néolithique ancien et final roussillonnais. Bulletin de la Société préhistorique française, 2001, 98 (3), pp.505-528. hal-00655857

\section{HAL Id: hal-00655857 https://hal.science/hal-00655857}

Submitted on 5 Apr 2020

HAL is a multi-disciplinary open access archive for the deposit and dissemination of scientific research documents, whether they are published or not. The documents may come from teaching and research institutions in France or abroad, or from public or private research centers.
L'archive ouverte pluridisciplinaire HAL, est destinée au dépôt et à la diffusion de documents scientifiques de niveau recherche, publiés ou non, émanant des établissements d'enseignement et de recherche français ou étrangers, des laboratoires publics ou privés. 


\title{
Persée
}

http://www.persee.fr

\section{L'Aspre del Paradis à Corneilla-del-Vercol (Pyrénées-Orientales) : contribution à l'étude du Néolithique ancien et final roussillonnais}

\author{
Jean-Denis Vigne;Laurent Bouby;Claire Manen;Denis Loirat \\ Bulletin de la Société préhistorique française, Année 2001, Volume 98, Numéro 3 \\ p. 505 - 528
}

\section{Voir l'article en ligne}

Le site de I 'Aspre del Paradis, localisé sur la commune de Corneilla-del- Vercol dans les Pyrénées-Orientales, présente plusieurs structures néolithiques révélées par la fouille d'une occupation de l'Antiquité tardive. Deux de ces structures (nos 5 et 6), assimilables à des fosses-silos, contiennent, en comblement secondaire, des restes de nature très variée. La troisième $\left(n^{\circ} 15\right)$ et dernière, est en revanche quasiment stérile. L'étude des restes archéologiques (céramique, faune, etc.) montre que le site a été occupé pendant deux périodes néolithiques bien distinctes. Les artefacts de chacune des fosses-silos sont décrits et replacés dans le contexte chrono- culturel régional. La première phase se rapporte à une occupation du Néolithique ancien, située à la charnière des $5 \mathrm{e}$ et $6 \mathrm{e}$ millénaires avant notre ère (Cardial récent, Epicardial ancien). En raison de la rareté des sites de plein air de cette époque, cette découverte, bien que ponctuelle, est remarquable. La seconde phase est illustrée par une occupation du Néolithique récent-final. Elle offre, notamment en raison de l'abondance des restes de torchis, le témoignage d'un habitat bien établi.

\section{Avertissement}

L'éditeur du site «PERSEE » - le Ministère de la jeunesse, de l'éducation nationale et de la recherche, Direction de l'enseignement supérieur, Sous-direction des bibliothèques et de la documentation - détient la propriété intellectuelle et les droits d'exploitation. A ce titre il est titulaire des droits d'auteur et du droit sui generis du producteur de bases de données sur ce site conformément à la loi n`98-536 du 1er juillet 1998 relative aux bases de données.

Les oeuvres reproduites sur le site «PERSEE » sont protégées par les dispositions générales du Code de la propriété intellectuelle.

Droits et devoirs des utilisateurs

Pour un usage strictement privé, la simple reproduction du contenu de ce site est libre.

Pour un usage scientifique ou pédagogique, à des fins de recherches, d'enseignement ou de communication excluant toute exploitation commerciale, la reproduction et la communication au public du contenu de ce site sont autorisées, sous réserve que celles-ci servent d'illustration, ne soient pas substantielles et ne soient pas expressément limitées (plans ou photographies). La mention Le Ministère de la jeunesse, de l'éducation nationale et de la recherche, Direction de l'enseignement supérieur, Sous-direction des bibliothèques et de la documentation sur chaque reproduction tirée du site est obligatoire ainsi que le nom de la revue et- lorsqu'ils sont indiqués - le nom de l'auteur et la référence du document reproduit.

Toute autre reproduction ou communication au public, intégrale ou substantielle du contenu de ce site, par quelque procédé que ce soit, de l'éditeur original de l'oeuvre, de l'auteur et de ses ayants droit.

La reproduction et l'exploitation des photographies et des plans, y compris à des fins commerciales, doivent être autorisés par l'éditeur du site, Le Ministère de la jeunesse, de l'éducation nationale et de la recherche, Direction de l'enseignement supérieur, Sous-direction des bibliothèques et de la documentation (voir http://www.sup.adc.education.fr/bib/ ). La source et les crédits devront toujours être mentionnés. 


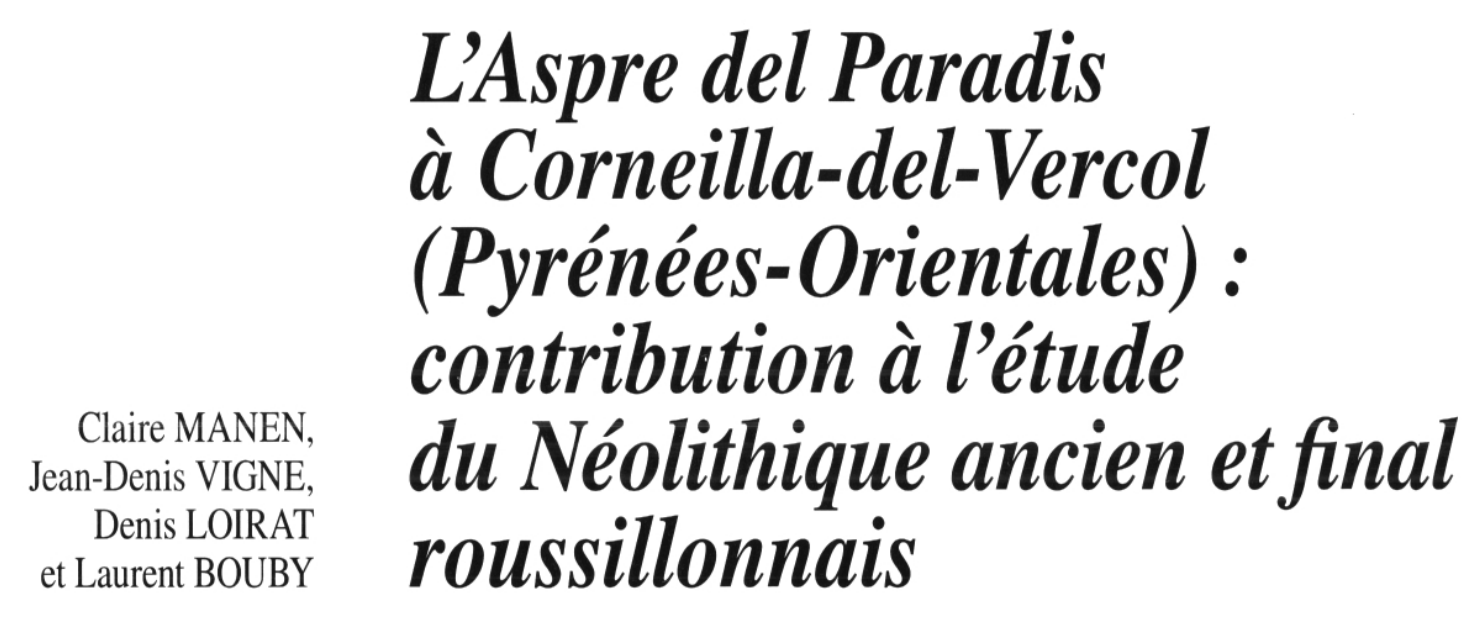

\begin{abstract}
Résumé
Le site de l'Aspre del Paradis, localisé sur la commune de Corneilla-delVercol dans les Pyrénées-Orientales, présente plusieurs structures néolithiques révélées par la fouille d'une occupation de l'Antiquité tardive. Deux de ces structures ( $n^{o s} 5$ et 6), assimilables à des fosses-silos, contiennent, en comblement secondaire, des restes de nature très variée. La troisième $\left(n^{\circ} 15\right)$ et dernière, est en revanche quasiment stérile. L'étude des restes archéologiques (céramique, faune, etc.) montre que le site a été occupé pendant deux périodes néolithiques bien distinctes. Les artefacts de chacune des fosses-silos sont décrits et replacés dans le contexte chrono-culturel régional. La première phase se rapporte à une occupation du Néolithique ancien, située à la charnière des $5^{e}$ et $6^{e}$ millénaires avant notre ère (Cardial récent, Épicardial ancien). En raison de la rareté des sites de plein air de cette époque, cette découverte, bien que ponctuelle, est remarquable. La seconde phase est illustrée par une occupation du Néolithique récent-final. Elle offre, notamment en raison de l'abondance des restes de torchis, le témoignage d'un habitat bien établi.
\end{abstract}

\begin{abstract}
The Aspre del Paradis site, located at Corneilla-del-Vercol (PyrénéesOrientales), has yielded several Neolithic structures revealed by the excavation of a Late Roman occupation. Two of these structures (nos. 5 and 6), comparable to storage pits, have been secondarily filled with various artefacts. The third (no. 15), and last, is almost sterile. The study of the archaeological remains (ceramics, fauna, etc.) reveals two distinct occupation periods during the Neolithic. The artefacts found in each storage pit are described and set in their regional chrono-cultural context. The first period is related to the Early Neolithic, at the turning point of the fifth and sixth millennia BC (Late Cardial, Early Epicardial). Because of the scarcity of open-air sites dating from this period, this discovery is remarkable. The second phase is characteristic of the Late Neolithic. Especially because of the abundance of cob, it points to a well-established dwelling.
\end{abstract}

Les établissements néolithiques de la région comprise entre la Montagne noire et la Catalogne moyenne sont assez nombreux et permettent d'esquisser un schéma chronoculturel global. Leur répartition géographique n'indique pas de préférence pour des domaines particuliers, les occupations en grotte ou abri sont très 
fréquentes tout au long de cette période (Guilaine, 1986; Bails, 1991 ; Martín Còlliga, 1992a et b ; Claustre et Vaquer, 1995; Martín Còlliga et Vaquer, 1995).

C'est à partir des fouilles de $\mathrm{J}$. Guilaine à la grotte Gazel (Sallèles-Cabardès, Aude) que les bases de la séquence chronoculturelle du Néolithique ancien languedocien et catalan furent construites (Guilaine, 1970 et 1986). Plus récemment, la découverte de sites tels que La Draga (Banyoles, Gerone) ou Plansallosa (Tortellá, Gerone) a permis d'affiner le découpage proposé mais également d'enrichir les connaissances sur les habitats de plein air et sur les rapports à l'environnement (Tarrús et al., 1992; Bosch et al., 1998). Dans la plaine du Roussillon, les découvertes récentes sont plus rares. On signalera cependant l'occupation épicardiale des Berges du Tech (Martzluff et al., 1995).

Les témoignages du Néolithique moyen sont en revanche beaucoup mieux documentés de part et d'autre des Pyrénées, et ce, pour des gisements de types très variés (Vignaud, 1990 et 1992; Claustre et Vaquer, 1995 ; Martín Cólliga et Villalba Ibañez, 1999). Nous ne développerons cependant pas cet aspect puisque le site de Corneilla-del-Vercol n'a livré aucun vestige de cette période.

Enfin, le Néolithique récent-final des régions roussillonnaises et catalanes est principalement caractérisé par le groupe de Véraza. Cependant, les nuances stylistiques de la céramique laissent entrevoir une périodisation complexe de ce groupe qui, de plus, côtoie plusieurs sphères d'influences distinctes (Vaquer, 1980). Dans la plaine du Roussillon, les sites du Néolithique final sont assez peu nombreux (Abelanet, 1980; Marsac, 1990). En Catalogne moyenne en revanche, le groupe de Véraza est représenté par de très nombreux sites qui permettent la construction d'un cadre socio-économique particulièrement développé (Martín Cólliga, 1992b).

\section{CIRCONSTANCES DE LA DÉCOUVERTE ET PRÉSENTATION DU SITE}

Le site de l'Aspre del Paradis se situe sur la commune de Corneilla-del-Vercol, dans les Pyrénées-Orientales

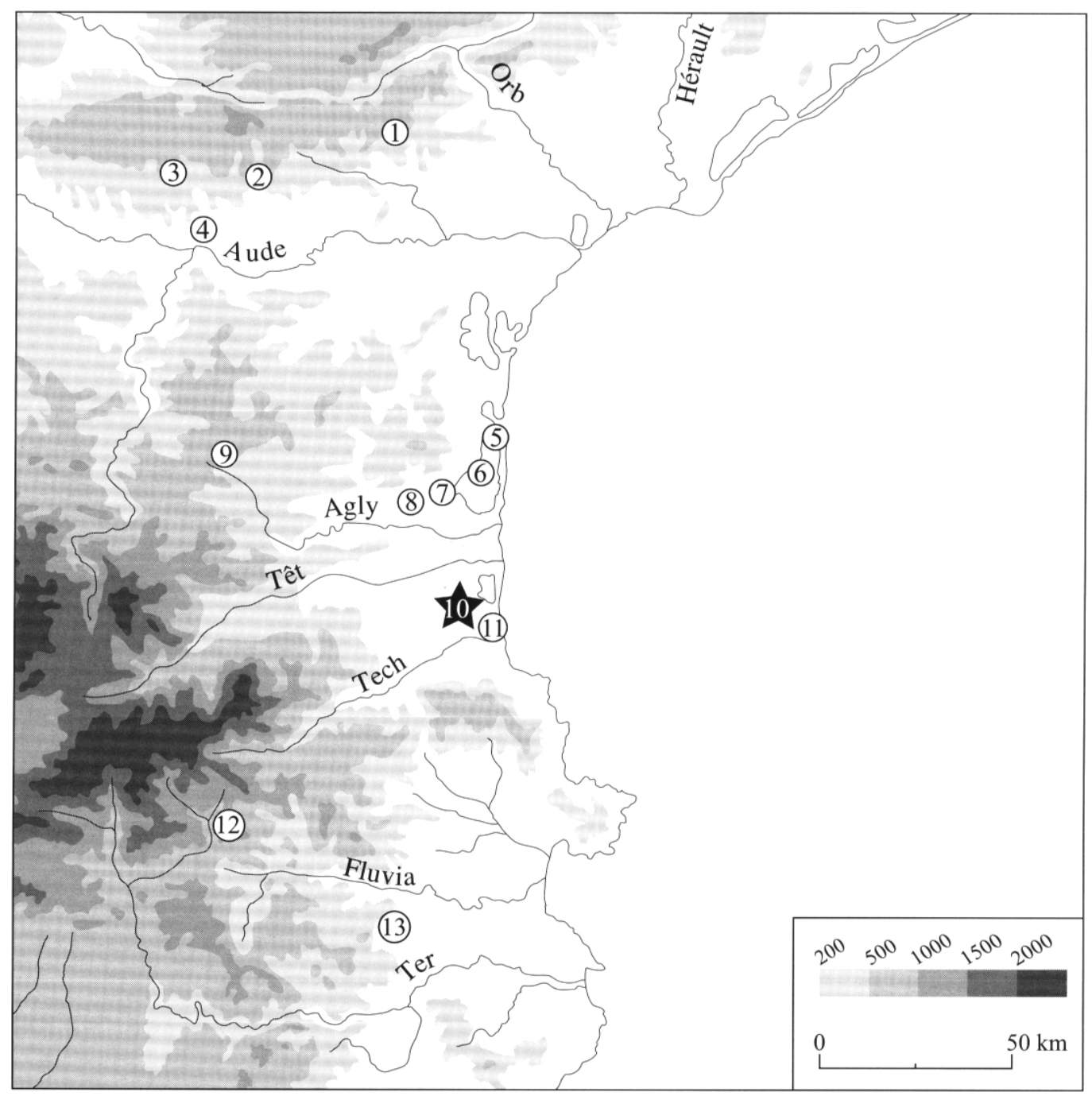

Fig. 1 - Situation du gisement et des principaux sites du Néolithique ancien et final. Hérault : 1. Camprafaud (Saint-Pons-deThommières), Aude : 2. Grotte de Gaougnas (Cabrespine), 3. Grotte Gazel (Sallèles-Cabardès), 4. Abri de Font-Juvénal (Conques-sur-Orbiel), 5. Grotte des Fées (Leucate), 6. La Corrège (Leucate), Pyrénées-Orientales : 7. Cova de l'Espérit (Salses), 8. Las Bruixes (Tautavel), 9. Grotte de Chincholle (Camps-sur-l'Agly), 10. Aspre del Paradis (Corneilla-del-Vercol), 11. Berge du Tech (Elne), Gérone : 12. Plansallosa (Tortellá), 13. La Draga (Banyoles). 
(fig. 1). Il est implanté au sein de la plaine roussillonnaise, à une dizaine de kilomètres du littoral. Il est bordé par plusieurs dépressions fermées, anciens étangs comblés au cours de l'Holocène par une sédimentation alluviale.

Durant une campagne de diagnostic réalisée par A. Pezin (AFAN) sur une occupation de l'Antiquité tardive, trois structures néolithiques, dispersées sur une surface de plus de $350 \mathrm{~m}^{2}$, ont été révélées. La fossesilo 5 présentait un profil en ampoule ( $1,70 \mathrm{~m}$ de diamètre maximal pour une profondeur conservée de $1 \mathrm{~m}$ ). Selon les observations faites à la fouille par A. Pezin, son comblement, rapide, a été effectué en deux temps. Le fond de la structure était comblé par un sédiment argileux brun noir très riche en mobilier. Le sommet, en revanche, était rempli d'un sédiment brun-noir extrêmement compact et stérile. Cette structure a été recoupée à la pelle mécanique, une moitié seulement a donc été fouillée finement. Le mobilier récolté, varié, se rapporte au Néolithique ancien. Le silo 6 était préservé sur environ $0,50 \mathrm{~m}$ de profondeur pour un diamètre maximal de 1,40 m. Le comblement, homogène, était composé d'un sédiment sablo-limoneux brun foncé à noir. Le mobilier exhumé est à rattacher au Néolithique récent-final. Enfin, le silo 15 offrait un diamètre maximal de 1,30 m pour une profondeur conservée de $1 \mathrm{~m}$. Sa morphologie et son comblement le rapprochent du silo 5. Le matériel est en revanche quasiment absent si l'on excepte deux fragments de céramique modelée atypiques. Il ne sera donc pas question de cette dernière structure dans cet article.

\section{LES RESTES ARCHÉOLOGIQUES}

\section{Le Néolithique ancien : le silo 5}

\section{La céramique}

Le silo 5 a livré un total de 38 tessons dont la plus grande dimension est supérieure ou égale à $1 \mathrm{~cm}$. On peut y ajouter une trentaine de fragments informes dont la plus grande dimension ne dépasse pas $1 \mathrm{~cm}$. Ces derniers ne seront pas pris en compte dans l'étude qui suit. Le taux de fragmentation présenté par ces restes est important : la dimension moyenne est de $5 \mathrm{~cm}$ avec un écart type de 3 . Les 38 tessons récoltés appartiennent à 24 vases au minimum. L'état des tessons est assez convenable même si, dans la majeure partie des cas, les fragments ont perdu leur surface d'origine. Il est ainsi difficile de distinguer les techniques employées pour le

\begin{tabular}{|l|c|}
\hline TYPES DE RESTES & $\begin{array}{c}\text { Nbre } \\
\text { de restes }\end{array}$ \\
\hline Indéterminé & 29 \\
\hline Bord & 2 \\
\hline Bord et panse & 1 \\
\hline Préhension & 4 \\
\hline Bord, panse et préhension & 2 \\
\hline Total & 38 \\
\hline
\end{tabular}

Tabl. 1 - Fosse-silo 5 : distribution des différents types de tessons en nombre de restes. montage et la finition des récipients. Ces restes se répartissent en différents types précisés dans le tableau 1.

\section{Description des individus}

À partir des 38 fragments récoltés, il est possible de reconstituer un nombre minimum de 24 individus parmi lesquels 9 sont décorés (14 fragments).

L'individu 1 (fig. 2), constitué par 6 fragments, correspond à un récipient de grande taille (épaisseur = $1,5 \mathrm{~cm})$. Le dégraissant, de taille homogène, est très abondant. Il est majoritairement composé de grains de feldspath détritique. On observe également la présence plus ponctuelle de quartz et de calcite. Les 6 fragments constituant ce vase comprennent 5 pièces indéterminées et une large anse en ruban verticale (hauteur $=12 \mathrm{~cm}$, largeur du ruban $=6 \mathrm{~cm}$, dégagement $=4,3 \mathrm{~cm}$ ). La particularité de ce vase réside dans son décor. Quatre fragments (dont celui de l'anse) présentent un décor de pastilles appliquées, plus ou moins circulaires, à relief peu prononcé (fig. 2, nos 1 à 3). Ces pastilles sont très peu espacées les unes des autres. Un cinquième tesson, appartenant au même vase, montre l'association de pastilles et de cordons (fig. 2, $n^{\circ} 4$ ). Les pastilles s'organisent de la même manière que précédemment. Les cordons sont très peu proéminents (environ $0,3 \mathrm{~cm}$ de hauteur). Le dernier élément que l'on peut rattacher à cet individu ne présente quant à lui qu'un cordon lisse, de type identique aux précédents (fig. $2, n^{\circ} 5$ ). La thématique décorative générale est difficilement définissable du point de vue de son organisation et de sa position sur le vase.

L'individu 2, figuré par un seul tesson, est un fragment de vase de type "bol hémisphérique" à bord droit et lèvre arrondie (fig. $3, \mathrm{n}^{\circ} 1$ ). Son diamètre à l'ouverture était de $12 \mathrm{~cm}$ pour une hauteur approximative de $8,2 \mathrm{~cm}$, soit un volume d'environ 0,61 . Une petite anse en ruban verticale (hauteur $=3,3 \mathrm{~cm}$, largeur du ruban $=1,7 \mathrm{~cm}$, dégagement $=1,4 \mathrm{~cm}$ ) se développe dans la partie médiane du récipient. La pâte présente un aspect lité tandis que le dégraissant, très fin, principalement composé de quartz, est peu abondant. La couleur noire de ce vase suggère une cuisson réductrice homogène. Des traces de lissage régulier sont bien visibles sur la paroi externe. Le décor est particulier puisqu'il mêle les cordons lisses disposés en "V", partant de l'anse et rejoignant le bord, et le décor au Cardium. Les deux cordons sont fins et saillants, de section triangulaire. Les impressions au Cardium sont réalisées en imprimant la coquille perpendiculairement à la pâte (aspect fusiforme des empreintes). Elles sont disposées verticalement et forment un ruban horizontal se développant sous le bord.

L'individu 3, représenté par un seul tesson, présente une pâte granuleuse, sableuse. Le dégraissant, de taille hétérogène, est principalement composé de quartz et de calcite. La cuisson est réductrice. Ce vase pourrait être rapproché du précédent car il offre une thématique décorative proche. On retrouve en effet un décor de cordons lisses saillants partant d'un élément de préhension très fragmenté pour rejoindre le bord (fig. $3, \mathrm{n}^{\circ} 2$ ). Cependant, la préhension est cette fois un mamelon vertical allongé. De plus, les cordons s'orientent verticalement 

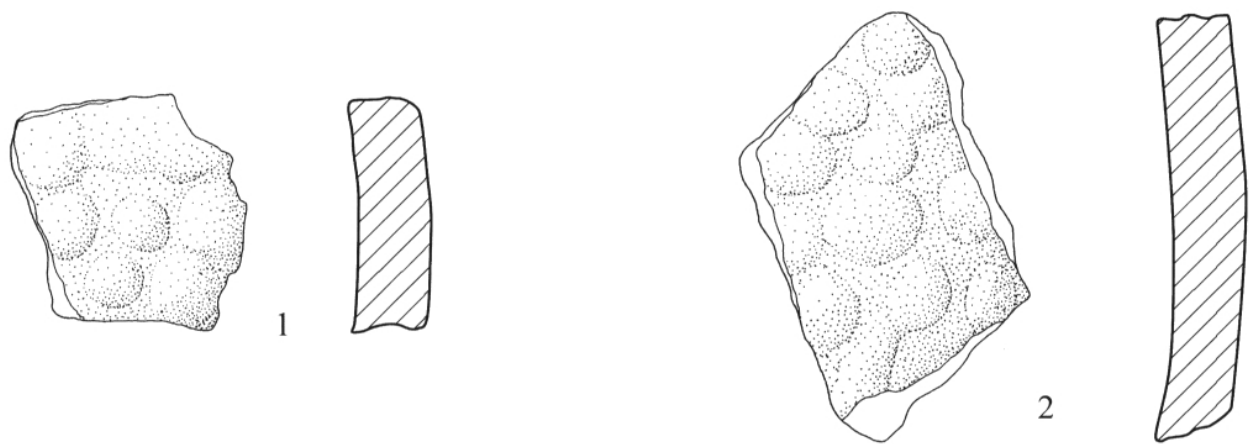

0 $3 \mathrm{~cm}$
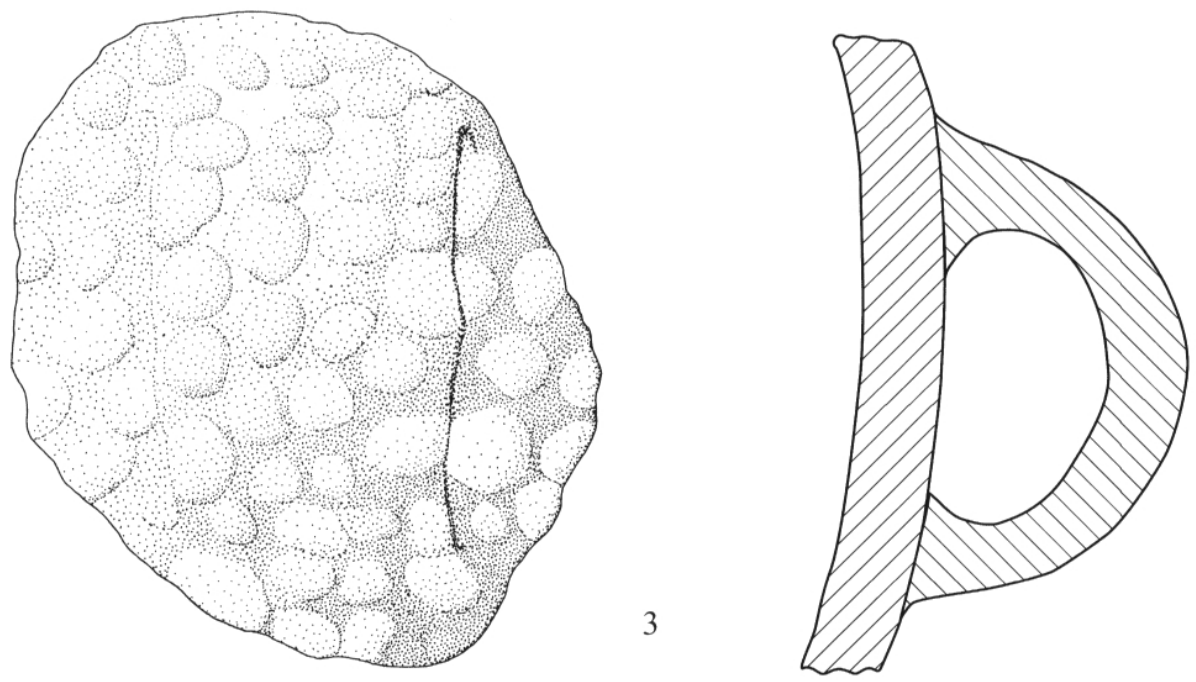
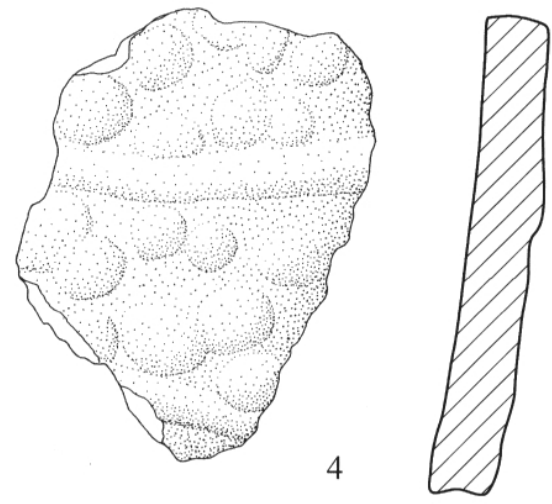
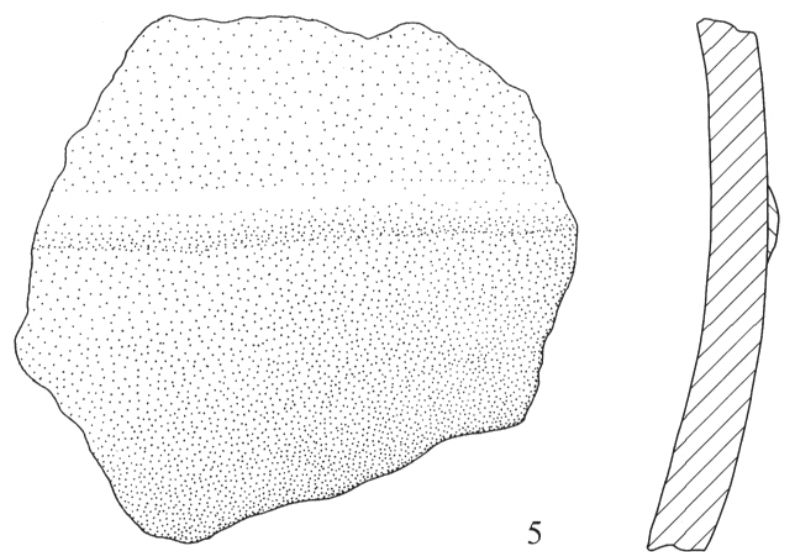

Fig. 2 - Fosse-silo 5 : vase décoré de pastilles et de cordons. 1-3 : pastilles appliquées; 4 : pastilles et cordons lisses; 5 : cordon lisse.

de la préhension vers le bord. Cet individu correspond probablement à un bol du même type que le précédent mais il n'est pas possible d'en proposer une reconstitution graphique.

L'individu 4, représenté par un seul tesson, est un fragment de type indéterminé (fig. $3, n^{\circ} 3$ ). La pâte présente un aspect vacuolé, peu compact. Le dégraissant, fin et peu visible, se rapproche de celui de l'individu 1. Étant donnés l'aspect de la pâte et la légèreté de la pièce, on peut penser que ce vase a subi une cuisson réductrice prolongée. Le décor consiste en de simples petits cordons lisses, plus ou moins réguliers, alignés parallèlement les uns aux autres. Leur orientation semble verticale. 

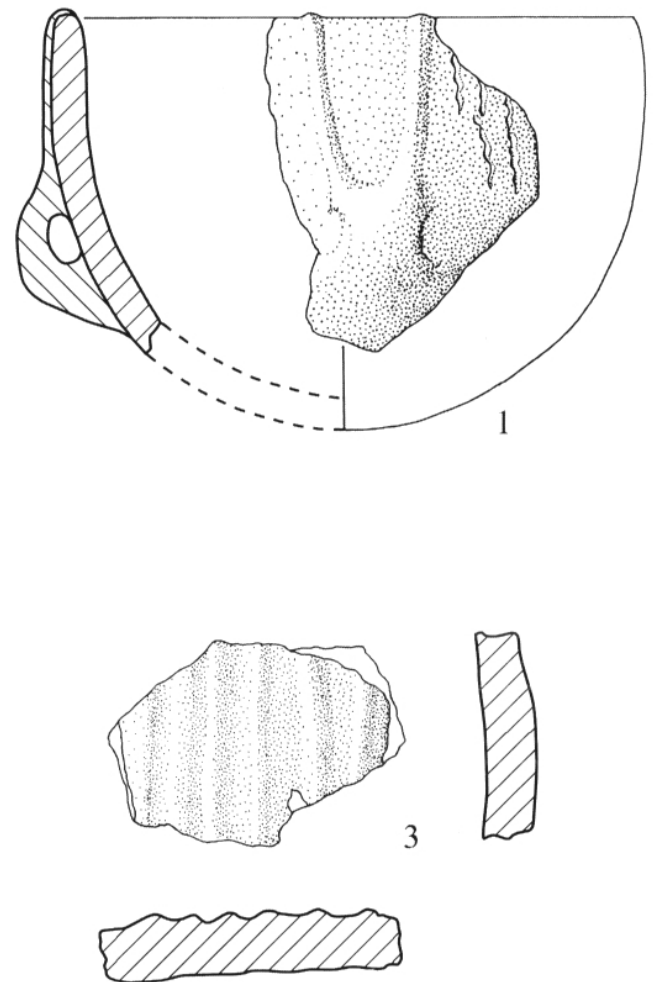

0 $3 \mathrm{~cm}$
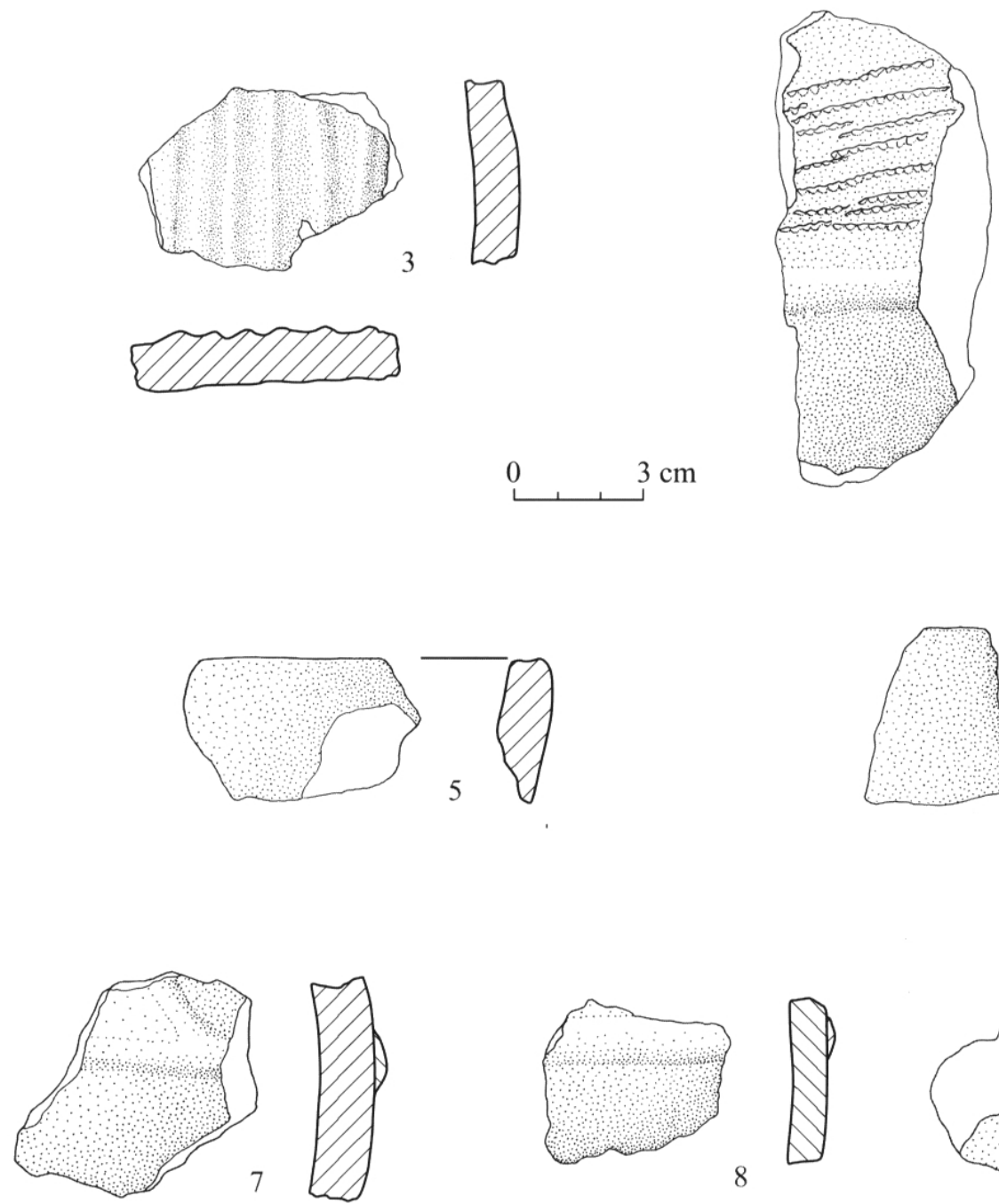

4
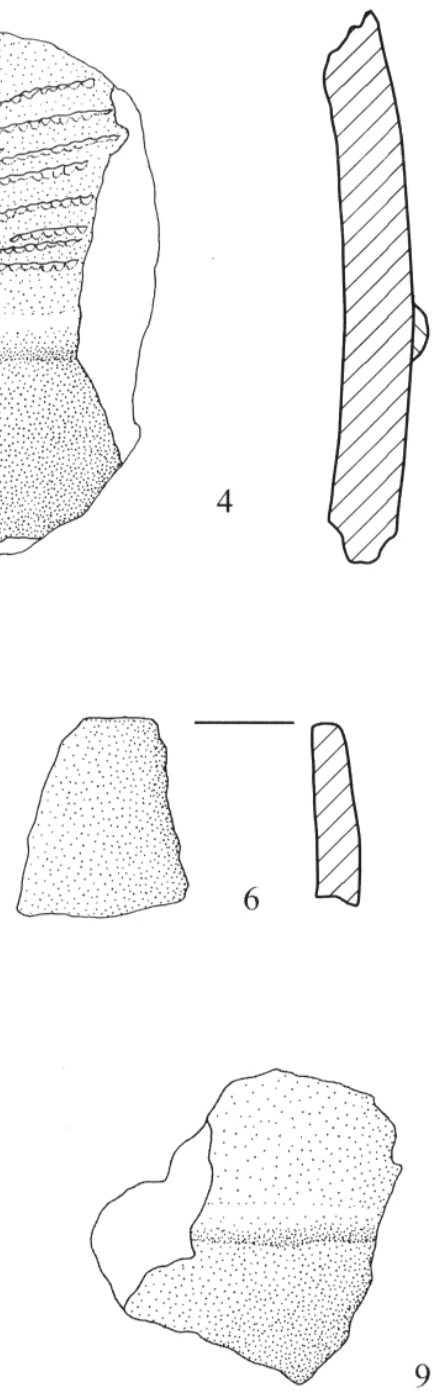

9

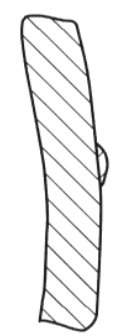

Fig. 3 - Fosse-silo 5 : décors au Cardium et décors plastiques. 1 : bol décoré d'impressions au Cardium et de cordons lisses disposés en V; 2 : cordons lisses disposés en V; 3 et 7-9: cordons lisses; 4 : décor au Cardium limité par un cordon lisses; 5-6: bords non décorés.

L'individu 5, représenté par un seul tesson, montre une pâte compacte d'aspect sablo-marneux (fig. $3, n^{\circ} 4$ ). Le dégraissant, de taille très hétérogène, est constitué de quartz, de calcite et, plus ponctuellement de mica. La couleur orange des surfaces interne et externe indique la pratique d'une cuisson complète en atmosphère oxydante. Le tesson est de type indéterminé et comporte un décor où se mêlent cordon et impressions au Cardium. Les impressions sont horizontales, réalisées perpendiculairement à la pâte, et disposées en lignes parallèles. Elles forment un ruban horizontal margé dans sa partie inférieure par le cordon lisse, peu proéminent.

L'individu 6, représenté par un seul tesson, est un fragment de bord dont le diamètre à l'ouverture n'est pas 
déterminable (fig. $3, \mathrm{n}^{\circ}$ 5). La pâte est compacte, d'aspect granuleux-sableux. Le dégraissant, relativement fin, est constitué de quartz, de mica et de calcite. Le tesson, de couleur brun-noir, a subi une cuisson réductrice homogène. La lèvre est biseautée. Ce fragment ne porte aucun décor. On notera la présence, sous la lèvre, d'un probable départ de préhension arrachée.

L'individu 7 est un fragment de bord dont le diamètre à l'ouverture n'est pas déterminable (fig. $3, n^{\circ} 6$ ). La pâte, compacte, est d'aspect sableux. Le dégraissant, composé de quartz et de calcite, est de taille hétérogène. La couleur brun-noir du tesson suggère une cuisson réductrice homogène. La lèvre est aplatie tandis que l'orientation du bord semble droite. Ce fragment ne porte aucun décor.

L'individu 8, est représenté par un fragment de type indéterminé (fig. 3, $\mathrm{n}^{\circ} 7$ ). La pâte est compacte, d'aspect sableux. Le dégraissant, très grossier, est apparent. La surface interne ainsi que la tranche sont oranges tandis que la surface externe est de couleur brune. La cuisson a donc été partiellement oxydante. Ce tesson porte un décor de cordons lisses fins et peu proéminents. La fragmentation empêche de déterminer le développement du décor. On peut cependant observer que les deux cordons se rejoignent en $\mathrm{V}$.

L'individu 9 consiste en un fragment de type indéterminé (fig. $3, \mathrm{n}^{\circ} 8$ ). La pâte est d'aspect sableux-marneux. Le dégraissant, abondant, est de taille hétérogène. Il est composé de quartz et de calcite. La face interne et le cœur du tesson sont noirs tandis que la face externe présente une couleur brique. La cuisson a donc été partiellement réductrice. Ce tesson porte un décor de cordon lisse dont le développement et l'orientation ne sont pas déterminables.

L'individu 10 est représenté par un fragment de type indéterminé (fig. 3, n 9). La pâte est d'aspect sableuxmarneux. Le dégraissant, apparent, est de taille très variable. Il est composé de quartz, de calcite et plus rarement de mica. La surface interne est noire tandis que la tranche et la surface externe sont rouge brique, indiquant la pratique d'une cuisson partiellement réductrice. Ce tesson porte un cordon lisse fin et peu proéminent. Le développement et l'orientation de ce décor ne peuvent être caractérisés.

L'individu 11 consiste en un fragment de préhension, probablement de type anse en ruban verticale, duquel partent des cordons lisses (fig. $4, \mathrm{n}^{\circ} 1$ ). La pâte est compacte, d'aspect sableux. Le dégraissant, composé de quartz et de calcite, est de taille très hétérogène. En raison de la fragmentation de ce tesson, il n'est pas possible de déterminer l'organisation générale du décor. On peut cependant observer le départ, depuis l'anse, de 4 cordons lisses, fins, et peu épais. Si l'on admet que l'anse est verticale, deux de ces cordons partent verticalement de son sommet. Les deux autres semblent se développer horizontalement.

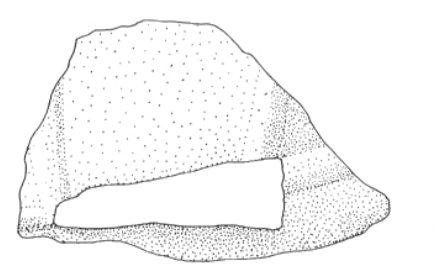

1

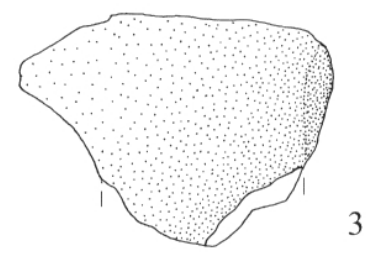

3
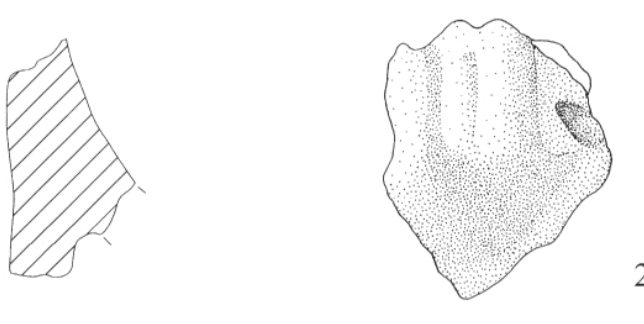

2

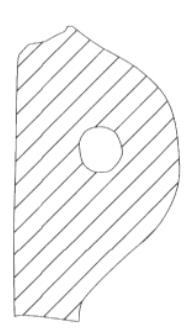

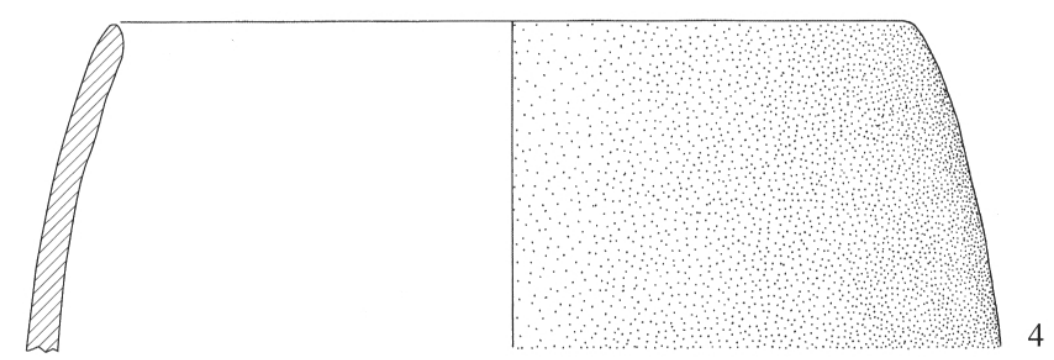

Fig. 4 - Fosse-silo 5 : éléments de préhension et vase non décoré. $1:$ anse en ruban brisée et associée à un décor de cordons lisses; 2 : anse à ensellement médian; 3 : fragment de anse en ruban; $4:$ marmite non décorée. 
L'individu 12 est figuré par un fragment de préhension. La pâte est d'aspect granuleux. Le dégraissant, composé de quartz et de calcite, est de taille hétérogène. La face interne et la tranche du tesson sont de couleur noire. La face externe est brun clair. Ces couleurs suggèrent la pratique d'une cuisson réductrice. Le type de préhension est très particulier (fig. $4, \mathrm{n}^{\circ} 2$ ). Il s'agit d'une anse en ruban, très peu dégagée de la panse (hauteur $=4,5 \mathrm{~cm}$, largeur du ruban $=3,5 \mathrm{~cm}$, dégagement $=1,5 \mathrm{~cm}$ ), à ensellement médian très prononcé.

L'individu 13 est représenté par un fragment de préhension de type anse en ruban (fig. $4, \mathrm{n}^{\circ} 3$ ). La pâte est d'aspect granuleux. Le dégraissant, composé de quartz, de calcite et de mica, est hétérométrique. La couleur des surfaces et de la tranche est rouge brique.

L'individu 14, représenté par 5 fragments, appartient à un récipient à profil continu fermé (fig. $4, \mathrm{n}^{\circ} 4$ ). Le diamètre à l'ouverture est de $16,5 \mathrm{~cm}$. La fragmentation du vase ne permet pas d'en proposer une restitution graphique complète. La pâte est vacuolée, d'aspect granuleux. Le dégraissant est très fin et peu visible (quelques grains de quartz). La couleur orangée du vase suggère une cuisson oxydante homogène. La lèvre est amincie tandis que le bord est rentrant. Ce vase ne porte aucun décor.

Les fragments restants appartiennent à environ une dizaine d'individus supplémentaires. Ils sont tous de type indéterminé et ne présentent pas de décor. C'est pourquoi ils ne feront pas l'objet d'une présentation détaillée.

\section{Discussion}

Du point de vue de l'aspect de la pâte, la majorité des tessons récoltés présente une pâte sableuse à tendance marneuse. La plaine du Roussillon étant constituée de terrasses de sables littoraux et d'argile pliocènes et quaternaires, les sources en matière première sont nombreuses. Les massifs granitiques environnants ont $\mathrm{pu}$ livrer l'essentiel des composants du dégraissant, sous forme de composants détritiques dans les unités sédimentaires (Barnett, 1989). Aucun travail de tri des grains n'a été réalisé pour la préparation de ce dégraissant. L'analyse des traces de façonnage et de finition se heurte à la fragmentation de la série. On peut cependant observer que les vases sont assez épais, puisque l'épaisseur moyenne des tessons est de $1 \mathrm{~cm}$ avec un écart type de 0,3 (soit un coefficient de variation faible de $28 \%$ ). La couleur de la tranche et des surfaces des tessons suggère la pratique de cuissons réductrices ou oxydantes. Dans $70 \%$ des cas, la couleur est homogène de la face inférieure à la face supérieure du tesson et indique la pratique d'une cuisson totalement oxydante ou réductrice. D'un point de vue morphologique, les éléments conservés sont rares. On ne peut qu'observer la présence de petits et grands récipients. Pour ces derniers, il n'est pas possible de reconstituer de forme particulière. Les petits et moyens récipients appartiennent aux types "bols" (petits vases subsphériques plus ou moins profonds) ou "marmites" (vase profond et légèrement fermé, à profil hémisphérique). Les éléments de préhension sont variés : anse en ruban de taille diverse, anse à ensellement médian et mamelon allongé.

\begin{tabular}{|l|c|c|}
\hline & $\begin{array}{c}\text { Nbre } \\
\text { de restes }\end{array}$ & $\begin{array}{c}\text { Nbre } \\
\text { d'individus }\end{array}$ \\
\hline Cordon lisse & 10 & 9 \\
\hline Pastille & 5 & 1 \\
\hline Cardium & 2 & 2 \\
\hline Total & 17 & 12 \\
\hline
\end{tabular}

Tabl. 2 - Fosse-silo 5 : distribution des techniques décoratives en nombre de restes et d'individus.

Le mode de décoration des vases est dominé par l'application de cordons lisses (tabl. 2). Mais on observe également l'utilisation du Cardium et des pastilles appliquées.

Les motifs décoratifs associés au cordon lisse sont multiples : organisation en V (fig. 5a-b-g-h), cordons multiples (fig. 5c), cordon unique seul (fig. 5d) et cordon unique servant de limite à un autre décor (fig. 5e-f). Les décors au Cardium sont peu structurés. Il s'agit simplement de la juxtaposition d'impressions horizontales ou verticales pour former un ruban horizontal (fig. 5f-g). Les cordons et le décor au Cardium peuvent être associés (fig. 5f-g), de même que les cordons et les pastilles (fig. 5e-f). La thématique générale de ces décors est difficilement déterminable. On peut cependant observer que sur deux individus, pour lesquels on possède une idée du développement général du décor, celui-ci est limité au tiers supérieur du vase (fig. 5g-h). Remarquons également que l'élément de préhension semble former un élément de symétrie important dans la structuration du décor, notamment en ce qui concerne les cordons lisses (fig. 5 a-g-h).

À partir de ces caractéristiques générales et malgré le caractère réduit de la série, nous tenterons maintenant de préciser sa place au sein du Néolithique ancien méridional. Les sites littoraux les plus proches (fig. 1) sont

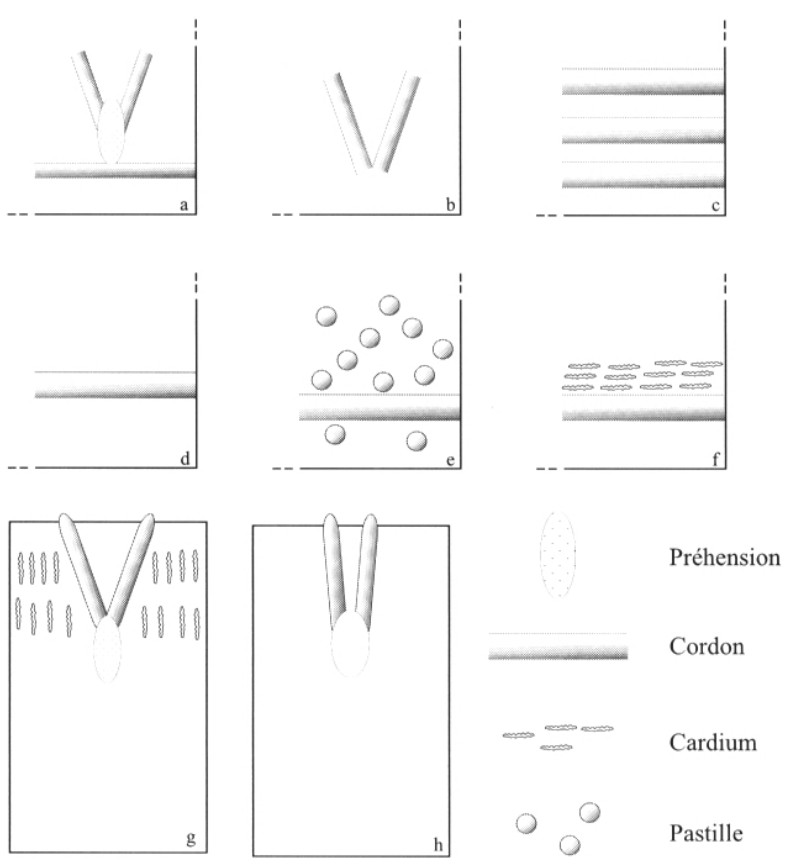

Fig. 5 - Schéma récapitulatif des motifs et des thèmes décoratifs de la céramique du silo 5 . 
ceux de la Corrège, de la grotte des Fées (Aude; Guilaine et al., 1984; Guilaine, 1985), de la Cova de l'Espérit (Pyrénées-Orientales; Martzluff et Abelanet, 1987) ou des Berges du Tech (Elne, PyrénéesOrientales; Martzluff et al., 1995). Malheureusement, aucun de ces gisements n'a fourni de séquence satisfaisante permettant d'établir un schéma d'implantation du Néolithique ancien dans cette zone géographique.

Du point de vue morphologique, on retrouve des éléments pouvant parfaitement être intégrés dans le panel des formes du Néolithique ancien du sud de la France ou de la Catalogne. Cependant, il n'est pas possible de préciser davantage cette attribution étant donné le caractère peu variable de la morphologie des vases au Néolithique ancien (Manen, 2000a et à paraître). On signalera toutefois que les anses à ensellement médian sont plus particulièrement fréquentes dans les phases récentes du Néolithique ancien (Gazel III-IV). Dans la région qui nous concerne, elles seront ensuite typiques du style de Montbolo.

Du point de vue de la décoration, nous rechercherons les assemblages céramiques qui offrent un décor réalisé à base de cordons lisses, parfois lié aux éléments de préhension, et/ou d'impressions au Cardium formant des décors peu complexes. Les meilleurs éléments de comparaison, proches du site, se retrouvent en Catalogne, dans la province de Gérone (fig. $1, \mathrm{n}^{\text {os }} 10$ et 11 ). Il s'agit des sites de La Draga (Tarrús et al., 1992 et 1994, fig. 1) et de Plansallosa, phase I (Bosch et al., 1998, fig. 21 à 24). Ils ont en effet livré des séries céramiques abondantes et homogènes. On y retrouve, comme à l'Aspre del Paradis, l'utilisation du cordon lisse et de la coquille de Cardium. La pastille n'est en revanche pas représentée. Dans les deux sites catalans, les cordons sont souvent peu proéminents. Ils constituent des motifs variés que l'on retrouve dans notre série : cordons simples, multiples, parallèles ou perpendiculaires. À La Draga, la technique décorative du cordon lisse est souvent associée à celle de l'impression au Cardium. Le(s) cordon(s) forme(nt) alors l'axe de symétrie ou la bordure du décor. Sur les deux sites, le Cardium est utilisé pour former des motifs décoratifs simples (rubans horizontaux ou verticaux, non margés, formés d'impressions parallèles). À Plansallosa (phase I), on remarque la présence de cordons verticaux dépassant la lèvre.

Dans cette même province de Gérone, plusieurs sites ont livré des ensembles céramiques décorés à base de cordons lisses (Bosch i Lloret, 1991). Cependant, ce décor est quasi-exclusif et n'est jamais associé à la technique du Cardium. Il s'agit principalement des sites de l'Avellaner, de la Cova 120, de la Cova S'Espasa ou de l'Ermitons qui appartiennent à un ensemble encore mal défini, centré sur le nord de la Catalogne, se développant entre 5000 et 4500 av. J.-C. (Bosch i Lloret, 1991). Ces assemblages ne peuvent pas être comparés à celui du silo 5 de l'Aspre del Paradis.

Dans les Pyrénées-Orientales, la série mise au jour dans les berges du Tech, sur la commune d'Elne, présente également de nombreux cordons lisses appliqués associés à des céramiques inornées et à deux tessons imprimés, l'un au doigt, l'autre au Cardium (Martzluff et al.,
1995, fig. 1 à 4). Dans l'Aude, les quelques restes céramiques récoltés dans la grotte des Fées (Leucate) montrent une décoration de cordons lisses utilisant, comme à l'Aspre del Paradis, l'élément de préhension comme axe de symétrie (Guilaine, 1985, fig. 1). On observe également la présence d'une anse à ensellement médian. Dans l'Aude toujours, la stratigraphie de la grotte Gazel constitue un élément de référence pour la compréhension du Néolithique ancien languedocien et catalan. L'utilisation de cordons lisses mais également de la coquille de Cardium est plutôt caractéristique de la phase II, épicardiale (Guilaine, 1986 ; Manen, 2000a, fig. 12). Les motifs réalisés au Cardium sont alors très simples. Quant aux cordons, ils présentent souvent la particularité d'être reliés à une anse en ruban et de se développer en $\mathrm{V}$ ou verticalement vers le bord. On retrouve la même thématique à Camprafaud c. 19-18 (Rodriguez, 1984, pl. X-XII-XXI). Cependant, ces cordons sont liés, à Gazel comme Camprafaud, à un décor de cannelures, inconnu à l'Aspre del Paradis.

Si l'on s'éloigne davantage de la plaine roussillonnaise, les cordons lisses dépassant le bord et les motifs simples réalisés au Cardium se retrouvent sur les séries céramiques de l'abri de la Tardive (Ardèche; Roudil et al., 1991, fig. 14 à 18) et de la grotte Lombard (Alpes-Maritimes; Binder, 1991, fig. 48 et 50). Ces deux ensembles sont rattachés à une phase récente du Cardial (Binder, 1991; Manen, 2000a). Les cordons lisses et les pastilles se retrouvent dans plusieurs sites géographiquement éloignés de l'Aspre del Paradis. La baume Bourbon (Cabrières, Gard), par exemple, livre un vase dont le décor de cordons et de pastilles est particulièrement proche de celui de l'Aspre del Paradis. On le retrouve également en Provence : abri de Saint-Mître, grande baume de Gémenos, baume de Fontbrégoua, abri du vieux Mounoï, abri des Seguins, le Baratin, abri de la Font des Pigeons et la grotte d'Unang (Binder et Courtin, 1986, fig. 2). Ce décor, ponctuellement représenté dans les assemblages, ne semble pas caractéristique d'une phase chrono-culturelle précise du Néolithique ancien.

D'une manière plus globale, on peut observer que l'utilisation des cordons lisses, en Languedoc et en Catalogne, devient très remarquable durant la phase récente du Cardial et la phase ancienne de l'Épicardial (Manen, 2000a). De même, l'utilisation de la coquille de Cardium pour former des thèmes peu complexes, en simple ruban non margé, est également plus typique d'une phase évoluée du Néolithique ancien (Binder dir., 1991 ; Manen, 2000a). Il semble donc probable que la série de l'Aspre del Paradis puisse être rattachée à une phase récente du Néolithique ancien, à la fin du sixième millénaire avant notre ère.

\section{Les restes fauniques}

\section{La microfaune}

Le silo 5 de l'Aspre del Paradis a livré 70 restes de petits et microvertébrés. Ils renvoient aux mammifères, aux reptiles, aux amphibiens et aux poissons (tabl. 3). Les premiers sont représentés par un fragment de sacrum de petit rongeur et par trois os d'un jeune lapin 


\begin{tabular}{|l|l|r|c|}
\hline \multicolumn{2}{|l|}{ Taxons } & NR & NMI \\
\hline Mammifères & Oryctolagus cuniculus & 3 & 2 \\
\hline Lapin & Rodentia & 1 & 1 \\
\hline Rongeur indét. & 14 & 1 \\
\hline Reptiles & Vipera sp. & 14 & 1 \\
\hline Vipère & 50 & 4 \\
\hline Amphibiens & Bufo bufo & 37 & 3 \\
\hline Crapaud commun & Pelobathes cf. cultripes & 1 & 1 \\
\hline Pélobate cultripède & Pér. & 2 & 1 \\
\hline Poissons & Dicentrarchus cf. labrax & 2 & 1 \\
\hline Loup
\end{tabular}

Tabl. 3 - Nature et fréquence des petits et microvertébrés de la fosse-silo 5 de l'Aspre del Paradis. NR, Nombre de Restes; NMI, Nombre Minimal d'Individus de fréquence.

(Oryctolagus cuniculus) dont rien n'indique qu'il a été consommé par l'homme. Un fragment crânien et 13 vertèbres ont probablement appartenu à une même vipère de bonne taille (Vipera sp.), probablement un aspic. Selon les critères de S. Bailon (1999), deux espèces de crapauds sont attestées : la très grande majorité des restes renvoie à toutes les régions squelettiques d'au moins trois crapauds communs de grande taille (Bufo bufo), alors qu'un seul ilion révèle la présence d'un pélobate (Pelobathes sp.), sans doute le pélobate cultripède ( $P$. cf. cultripes), seul représenté aujourd'hui dans la région (Lizana, Nöllert, in Gasc, 1997). La forte dominance des os de crapaud est typique des assemblages de petits et microvertébrés piégés naturellement dans les structures en creux (Vigne et al., 1994a et b; Lesur et Vigne, en prép.). Les deux vertèbres (déformées par le poids des sédiments) de loup (Dicentrarchus cf. labrax) renvoient en revanche à des déchets de consommation anthropique.

Caractéristiques, validité

et signification de la grande faune

L'essentiel du matériel faunique du silo 5 est constitué d'un volume appréciable d'ossements de grande faune, représentant plus de $10 \mathrm{~kg}$. Au regard de cette masse, l'assemblage se caractérise toutefois par une petite quantité de pièces : le nombre de restes (NR) déterminés n'est que de 254 , mais ils représentent près de $80 \%$ de la masse totale des vestiges (tabl. 4). La plupart d'entre eux a malheureusement été cassée à la fouille, augmentant artificiellement le nombre, initialement réduit, d'esquilles indéterminées. C'est pourquoi nous n'avons pas jugé utile de compter les fragments indé-

\begin{tabular}{|l|r|r|c|r|r|r|}
\hline \multirow{2}{*}{} & \multicolumn{2}{|c|}{ Bos } & \multicolumn{2}{c|}{ Cervus } & \multicolumn{2}{c|}{ Petits rum. } \\
\cline { 2 - 7 } & $\mathrm{PdR}$ & $\% \mathrm{PdR}$ & $\mathrm{PdR}$ & $\% \mathrm{PdR}$ & $\mathrm{PdR}$ & $\% \mathrm{PdR}$ \\
\hline Tête & 1945 & 25,9 & & & 192 & 50,0 \\
\hline Vertèbres & 1680 & 22,3 & & & 30 & 7,8 \\
\hline Côtes & 715 & 9,5 & & & 5 & 1,3 \\
\hline Scapula & 170 & 2,3 & & & 17 & 4,4 \\
\hline Humérus & 800 & 10,6 & & & 15 & 3,9 \\
\hline Radio-ulna & 210 & 2,8 & & & 12 & 3,1 \\
\hline Carpe & 60 & 0,8 & 35 & 14,5 & & \\
\hline Métacarpe & 347 & 4,6 & & & 8 & 2,1 \\
\hline Pelvis & 480 & 6,4 & & & 20 & 5,2 \\
\hline Fémur & 545 & 7,3 & & & 50 & 13,0 \\
\hline Tibia & & & & & 25 & 6,5 \\
\hline Tarse & 300 & 4,0 & 67 & 27,7 & & \\
\hline Métatarse & 190 & 2,5 & 140 & 57,9 & 7 & 1,8 \\
\hline Phalanges & 75 & 1,0 & & & 3 & 0,8 \\
\hline TOTAL & 7517 & 100 & 242 & 100 & 384 & 100 \\
\hline
\end{tabular}

Tabl. 5 - Fréquences absolues et relatives, en Poids de Restes (PdR), des parties du squelette des trois groupes taxinomiques représentés dans la fosse-silo 5 de l'Aspre del Paradis.

terminés et nous nous sommes contentés de les quantifier par leur masse. La plupart des pièces cassées a cependant pu faire l'objet de remontages, et ce de manière suffisamment satisfaisante pour procéder aux déterminations ostéologiques. Seul le corpus de données métriques a souffert des fractures dues à la fouille. Si l'on excepte l'effet de ces dernières, le matériel est donc dans un excellent état. Les surfaces osseuses sont suffisamment bien conservées pour qu'on décèle quelques traces de découpe. Les marques de morsures sont absentes, ce qui suggère un rejet rapide dans le sol, à l'abri des dents des carnivores. Le spectre anatomique des deux principaux groupes taxinomiques, les bovins et les petits ruminants (tabl. 5), indique que toutes les parties du squelette sont représentées, à l'exception des petits os des caprinés (carpe et tarse) et du tibia des bovins. La répartition quantitative des parties anatomiques, comparée en masse à celle d'un squelette actuel de référence (chèvre robuste, fig. 6), ne fait pas apparaître d'anomalie significative concernant les bovins. Pour les caprinés, on relève en revanche un excédent de pièces crâniennes et un déficit corrélatif du squelette axial, des membres (notamment l'antérieur) et des extrémités. Cela éclaire la nature du dépôt : il s'agit des pièces volumineuses, issues de la chaîne opératoire de découpe et de consommation de la viande, qui semblent avoir été assez systématiquement

\begin{tabular}{|c|c|c|c|c|c|c|c|c|}
\hline Groupes & NR & $\%$ NR & $\operatorname{PdR}(\mathrm{g})$ & $\%$ PdR & Dont espèces & NR & $\%$ NR & NMI \\
\hline \multirow{2}{*}{ Grands ruminants } & \multirow{2}{*}{174} & \multirow{2}{*}{68,5} & \multirow{2}{*}{7759} & \multirow{2}{*}{95,3} & Bœuf ('Bos taurus') & 37 & 70 & 3 \\
\hline & & & & & Cerf (Cervus elaphus) & $6^{\star}$ & 11 & 2 \\
\hline Petits ruminants & 80 & 31,5 & 384 & 4,7 & Mouton ('Ovis aries') & 10 & 19 & 6 \\
\hline Total déterminés & 254 & 100,0 & 8143 & 100,0 & Total & 47 & 100 & 11 \\
\hline Indéterminés & & & 1910 & 19,0 & & & & \\
\hline TOTAL & & & 10053 & & & & & \\
\hline
\end{tabular}

Tabl. 4 - Nature et fréquence des grands mammifères de la fosse-silo 5 de l'Aspre del Paradis. NR, Nombre de Restes ; NMI, Nombre Minimal d'Individus de fréquence. 


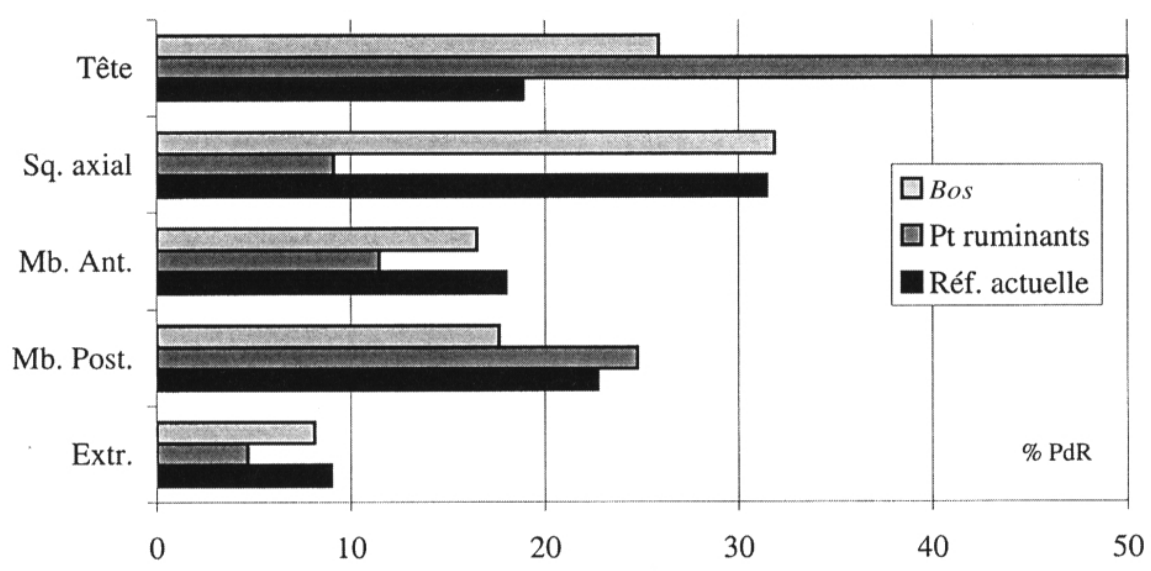

Fig. 6 - Fréquences relatives des grandes régions du squelette des bovins (Bos) et des petits ruminants de la fosse-silo 5 de l'Aspre del Paradis, exprimées en Poids de Restes (PdR) et comparées à celle d'un squelette actuel de chèvre adulte de Chypre (réf. actuelle).

(et rapidement) évacuées des zones de circulation, puis accumulées dans cette structure en creux, laissée quelques temps ouverte après sa réforme (piégeage naturel d'amphibiens). Cette conclusion implique que les plus petites pièces, notamment une partie des restes de caprinés et d'éventuelles autres espèces de même format, soient restées dans les couches de surface, aujourd'hui disparues.

Cela explique au moins en partie la faible diversité du spectre de faune tout comme la forte dominance des bovins ('Bos taurus'), aux alentours de $70 \%$ du NR et de $90 \%$ du poids de restes (PdR). Les caprinés représentent moins d'un quart des restes et seulement $5 \%$ de leur masse, mais décrivent un nombre minimal de six individus, contre trois seulement pour les bovins. Les dix pièces de petits ruminants qui ont pu être déterminées au rang du genre renvoient toutes au mouton
('Ovis aries') selon les critères de J. Boessneck et al. (1964), S. Payne (1969 et 1985), J. Clutton-Brock et al. (1990) et D. Helmer (2000). Aucun reste ne témoigne de la présence de la chèvre. Le cerf élaphe n'est figuré que par six os (11\% du NR, $3 \%$ du PdR) qui ne renvoient qu'à des pièces des extrémités (carpe, tarse en connexion et métatarsiens) de deux individus au moins. Une trace sur un talus atteste de la découpe.

\section{Morphologie des bovins et des ovins}

Le nombre probablement restreint de sujets de bovins impliqués dans l'assemblage, ainsi que, surtout, la rareté des pièces mesurables (une quinzaine si l'on exclut les dents; tabl. 6) incitent à considérer l'analyse métrique avec prudence. Il est d'autant plus difficile de se faire une idée du format général de ces animaux que les références métriques sur les bovins du Néolithique

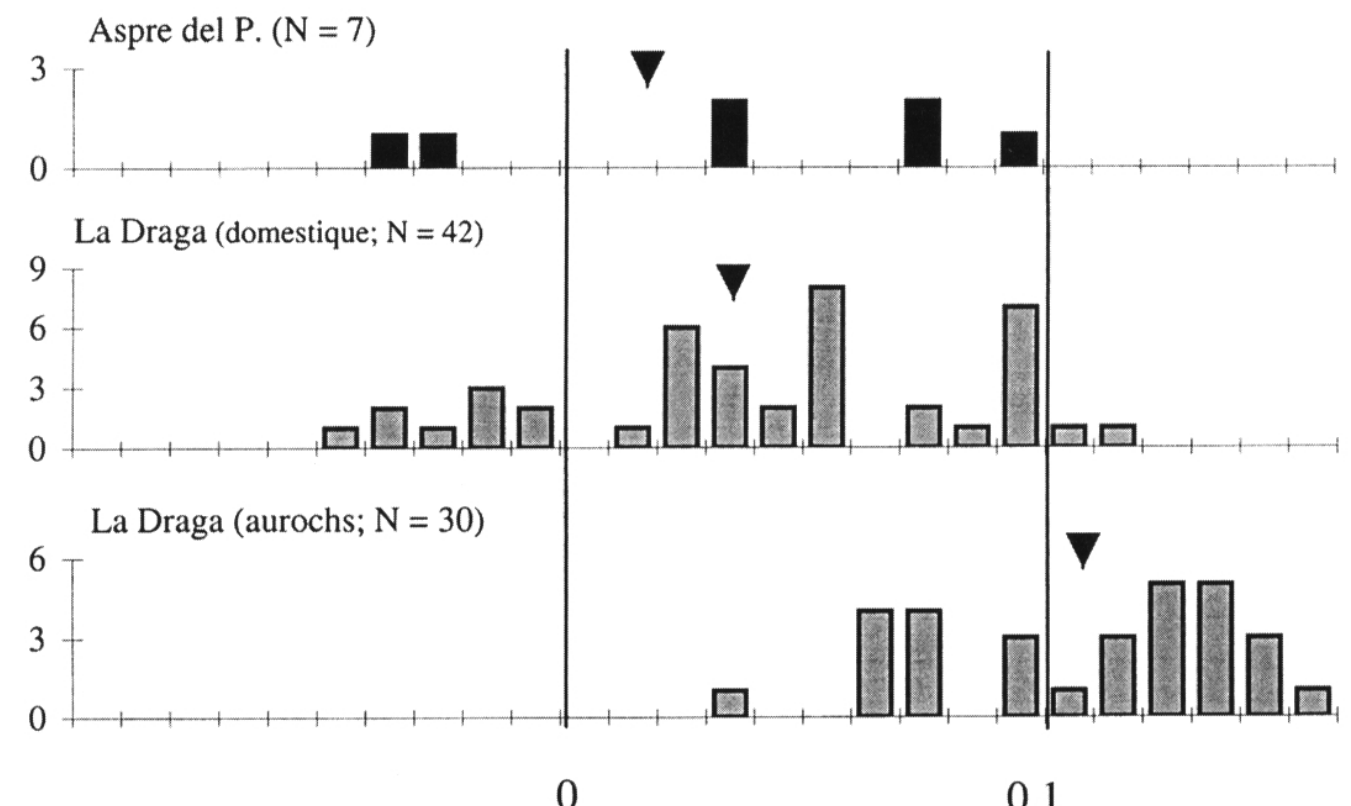

Fig. 7 - Dispersion des mensurations squelettiques des bovins de la fosse-silo 5 de l'Aspre del Paradis, exprimées en différences de log (référence : Meadow 1999) et comparées à celles des bovins domestiques et sauvages du Cardial de La Draga (d'après Saña i Segui, 1993). 
ancien du Midi de la France et de l'Est espagnol sont très peu nombreuses (Tresset et Vigne, sous presse). Le seul lot d'importance est celui issu du site cardial de La Draga (Banyoles, Gérone; Saña i Segui, 1993), et, compte tenu de la taille des échantillons respectifs, la seule méthode de comparaison possible est celle des log-ratios (Meadow, 1999).

La dispersion des mesures de bovins de l'Aspre del Paradis apparaît assez importante (fig. 7). Cette situation résulte en grande partie d'un artefact : les deux mesures les plus faibles appartiennent à des phalanges dont l'attribution au membre antérieur ou postérieur n'a pas pu être faite en raison de la petite taille de la série. Le fait qu'elles aient été intégrées dans le diagramme de log-ratios en tant que "indéterminées" augmente l'imprécision de leur situation relative et peut être seul à l'origine de leur situation basse, à l'écart des autres mesures. La moyenne des mesures des bovins de l'Aspre del Paradis est donc, en réalité, peut-être légèrement supérieure à celle qui apparaît sur la figure 7.

Quoi qu'il en soit, cette dispersion et cette moyenne sont très proches de celles observées sur le site de La Draga, dont les mesures les plus basses sont d'ailleurs probablement entachées du même biais méthodologique. Même si on ne peut pas exclure que les trois dimensions les plus fortes du site français renvoient à des aurochs femelles (de petite taille), l'ensemble décrit plus vraisemblablement des bovins domestiques. L'absence de valeurs supérieures à 0,1 exclut la présence d'aurochs mâles.

Il ressort de cette comparaison métrique que (i) les bovins de l'Aspre del Paradis sont vraisemblablement tous domestiques, (ii) comme on pouvait s'y attendre pour une phase initiale du Néolithique, ils sont de grande taille, et (iii) cette dernière est tout à fait comparable avec celle des bovins du site cardial catalan de La Draga, qui est malheureusement la seule référence métrique importante dont on dispose dans la région pour ces époques.

Les mensurations recueillies pour les caprinés sont tout à fait insuffisantes pour une approche de la caractérisation métrique. Toutefois, une cheville osseuse fortement endommagée (fig. 8) offre une orientation par rapport au toit crânien qui fait nettement pencher pour le mouton, probablement un bélier compte tenu de la robustesse de la paroi osseuse. Mais une carène antérieure prononcée, une section basale ovalaire, comprimée

'Bos taurus'
\begin{tabular}{|l|r|}
\hline 3e molaire \\
\hline \multicolumn{2}{|c|}{ DT } \\
\hline Sup. & 25,0 \\
Sup. & 25,6 \\
\hline Inf. & 18,0 \\
Inf. & 18,0 \\
\hline
\end{tabular}

\begin{tabular}{|c|c|c|c|c|}
\hline \multicolumn{5}{|c|}{ Métacarpe } \\
\hline $\mathrm{Bp}$ & $\mathrm{Dp}$ & $\mathrm{SD}$ & $\mathrm{Bd}$ & $\mathrm{Dd}$ \\
\hline 75,5 & 48,0 & 46,5 & & 31,3 \\
& & & 70,3 & 38,0 \\
\hline
\end{tabular}

\begin{tabular}{|c|c|c|}
\hline \multicolumn{3}{|c|}{ Scapula } \\
\hline GLP & BG & LG \\
\hline 67,7 & 48,0 & 60,7 \\
81,0 & & \\
\hline
\end{tabular}

\begin{tabular}{|c|c|}
\hline \multicolumn{2}{|c|}{ Humérus } \\
\hline Bd & Dd \\
\hline 104,8 & 89,7 \\
109,4 & 96,0 \\
\hline
\end{tabular}

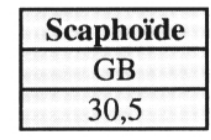

\begin{tabular}{|c|}
\hline Lunatum \\
\hline GB \\
\hline 31,0 \\
\hline
\end{tabular}

\begin{tabular}{|c|c|}
\hline \multicolumn{2}{|c|}{ Calcanéus } \\
\hline GL & GB \\
\hline 161,0 & 50,0 \\
\hline
\end{tabular}

\begin{tabular}{|r|r|c|}
\hline \multicolumn{3}{|c|}{ Talus } \\
\hline GLl & GLm & Bd \\
\hline 79,0 & 74,6 & 49,0 \\
\hline
\end{tabular}

\begin{tabular}{|c|c|}
\hline \multicolumn{2}{|c|}{ Métatarse } \\
\hline $\mathrm{Bd}$ & $\mathrm{Dd}$ \\
\hline 67,5 & 38,0 \\
& 35,0 \\
\hline
\end{tabular}

\begin{tabular}{|c|c|c|c|}
\hline \multicolumn{4}{|c|}{ Phalanges } \\
\hline & GL & $\mathrm{Bp}$ & $\mathrm{Bd}$ \\
\hline $\mathrm{Ph} .1$ & 72,3 & 32,2 & 33,6 \\
\hline $\mathrm{Ph} .1$ & 64,3 & 26,7 & \\
\hline $\mathrm{Ph} .2$ & 41,2 & 35,0 & 32,4 \\
\hline
\end{tabular}

Cervus elaphus

\begin{tabular}{|c|}
\hline Scaphoïde \\
\hline GB \\
\hline 24,2 \\
\hline
\end{tabular}

\begin{tabular}{|c|}
\hline Lunatum \\
\hline GB \\
\hline 26,3 \\
\hline Calca. \\
\hline GB \\
\hline 42,0 \\
\hline
\end{tabular}

\begin{tabular}{|c|c|c|c|c|}
\hline \multicolumn{5}{|c|}{ Talus } \\
\hline GLl & GLm & Dl & Dm & Bd \\
\hline 69,5 & 65,5 & 37,2 & 39,7 & 41,2 \\
74,5 & 67,8 & & & 42,4 \\
\hline
\end{tabular}

\begin{tabular}{|c|}
\hline Cuné. \\
\hline GB \\
\hline 34,7 \\
\hline
\end{tabular}

\begin{tabular}{|c|}
\hline Cubo-nav. \\
\hline GB \\
\hline 50,3 \\
\hline
\end{tabular}

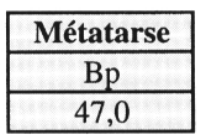

'Ovis aries'

\begin{tabular}{|c|c|}
\hline \multicolumn{2}{|c|}{ Cornillon } \\
\hline DAP & DT \\
\hline 45,2 & 25,0 \\
\hline
\end{tabular}

\begin{tabular}{|c|c|}
\hline 3e mol. inf. & \\
\hline DT & \\
\hline 6,7 & 5 \\
\hline 7,0 & 6, \\
\hline 6,8 & \\
\hline
\end{tabular}

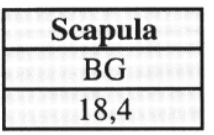

\begin{tabular}{|c|c|c|}
\hline \multicolumn{3}{|c|}{ Radius } \\
\hline Bp & Dp & SD \\
\hline 29,9 & 14,9 & 15,6 \\
\hline
\end{tabular}

Tabl. 6 - Mensurations (en mm) des restes de bœuf, de cerf et de mouton de la fosse-silo 5 de l'Aspre del Paradis. Pour les codes des mesures, voir Driesch, 1976. 


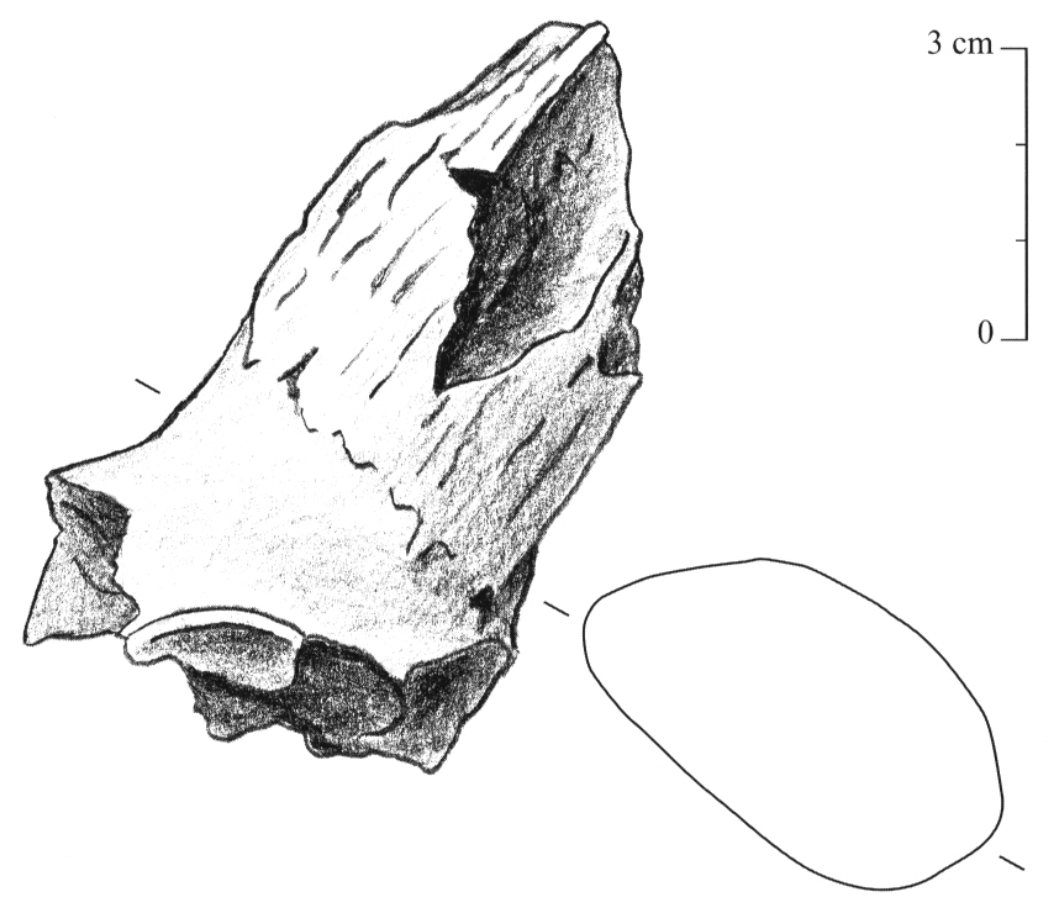

Fig. 8 - Vue latérale et section basale de la cheville osseuse gauche de bélier de la fosse-silo 5 de l'Aspre del Paradis (Dessin D.L.).

transversalement et une taille réduite dénotent une forme déjà très transformée par rapport aux types primitifs du Néolithique ancien de la Méditerranée occidentale.

\section{Âges d'abattage et gestion des troupeaux}

Pour les bovins, 12 dents représentent trois individus abattus respectivement entre deux et quatre ans, entre quatre et six ans et demi et entre six ans et demi et neuf ans (tabl. 7). Compte tenu de la taille très restreinte de l'échantillon, on doit se contenter de constater l'absence de jeunes, la présence d'un animal probablement abattu pour la viande (le plus jeune) et de deux bêtes tuées à un âge avancé et pouvant renvoyer à une utilisation pour des productions secondaires (vaches laitières de réforme?).

Pour les caprinés, on ne dispose que de six dents, mais le hasard de l'échantillonnage fait qu'elles correspondent à autant d'individus différents. Cela ne suffit pourtant pas pour avoir une idée statistique du profil d'abattage. Les deux bêtes tuées entre 2 et 12 mois ont pu

\begin{tabular}{|l|c|c|c|c|c|}
\hline Bos & $0-1$ & $1-2$ & $2-4$ & $4-6,5$ & $6,5-9$ \\
\hline $\mathrm{Nd}$ & 0 & 0 & 1 & 6 & 5 \\
\hline $\mathrm{NMI}$ & 0 & 0 & 1 & 1 & 1 \\
\hline Caprinés & $\mathrm{A}$ & $\mathrm{B}-\mathrm{C}$ & $\mathrm{D}$ & $\mathrm{E}-\mathrm{F}$ & $\mathrm{G}-\mathrm{I}$ \\
& $0-2 \mathrm{~m}$ & $2-12 \mathrm{~m}$ & $1-2 \mathrm{a}$ & $2-4 \mathrm{a}$ & de $4 \mathrm{a}$ \\
\hline $\mathrm{Nd}$ & 1 & 2 & 1 & 2 & 0 \\
\hline $\mathrm{NMI}$ & 1 & 2 & 1 & 2 & 0 \\
\hline
\end{tabular}

Tabl. 7 - Fréquences non corrigées des classes d'âge des bovins et des caprinés de la fosse-silo 5 de l'Aspre del Paradis, exprimées en nombre de dents (Nd) et en Nombre Minimal d'individus (NMI). Pour les bovins, les classes d'âge sont exprimées en années, sur la base des propositions de Ducos (1968). Pour les caprinés, elles sont exprimées en années (a) ou en mois (m), sur la base des travaux de Payne (1973), révisés par Helmer (1995). l'être pour leur viande. La présence d'un animal abattu très jeune, avant deux mois, renforcée par celle de deux bêtes tuées entre deux et quatre ans (brebis de réforme?), pourrait attester d'une utilisation pour le lait (Helmer et Vigne, en prép.).

Ainsi, les données concernant les courbes d'abattage sont très succinctes. Elles livrent cependant quelques indices de possibles productions secondaires, pour les bovins comme pour les caprinés.

\section{Éléments pour l'interprétation fonctionnelle et chronologique}

Qualitativement, la liste de faune est peu diversifiée, dominée par les espèces domestiques, bovins et mouton. On est surpris par l'absence de la chèvre et surtout du porc, qui donnent l'impression d'une spécialisation de l'élevage, difficile d'ailleurs à prendre en compte autrement que comme une situation locale résultant de la vision partielle qu'apporte un seul silo-dépotoir. Seul le cerf évoque la présence d'animaux sauvages, alors que deux vertèbres témoignent de la pratique de la pêche côtière.

Il est difficile de se fier aux données quantitatives du spectre de faune dans la mesure où, bien que peu affectée par la "fonte" taphonomique différentielle, elles sont probablement en partie biaisées par la nature même du dépôt qui résulte de l'accumulation des déchets de boucherie et de cuisine les plus encombrants dans une structure profonde restée momentanément ouverte. Cette situation favorise en effet les espèces de grande taille (bovins) au détriment des petites (caprinés et suinés). Il est cependant peu vraisemblable que les bovins aient été très minoritaires dans la subsistance des habitants du site, et on peut raisonnablement avancer qu'ils y tenaient une place non négligeable, aux côtés 
des caprinés. Avec l'attestation de deux individus au moins, le cerf dénote le recours à la chasse.

Nous avons donc affaire à une production carnée dominée par l'élevage mixte de bovins (peut-être dominants) et de moutons, mais tirant également profit de la chasse au grand gibier. Une telle stratégie diversifiée s'oppose à la spécialisation quasiment monospécifique de l'élevage du Néolithique ancien centro-méditerranéen et des sites pionniers qui en sont issus sur les côtes occidentales (Pendimoun, Pont de Roque-Haute). Elle s'inscrit en revanche parfaitement dans le cadre du Cardial (Vigne, 1998; Vigne et Helmer, 1999; Tresset et Vigne, 2000).

Plusieurs indices amènent par ailleurs à proposer une date relativement tardive à l'intérieur du Néolithique ancien. La possible dominance des bovins s'opposerait à l'abondance des caprinés qu'on note dans les assemblages anciens de Pont de Roque-Haute ou de Gazel (phase I), et rapprocherait l'assemblage de celui de La Draga, daté du Cardial récent (fin $6^{\mathrm{e}}$ et début $5^{\mathrm{e}}$ millénaires av. J.-C.; Bosch et al., 1999; Manen, 2000a). Mais les critères morphologiques sont plus convaincants à cet égard car ils ne sont pas biaisés par le mode d'accumulation des restes dans le silo. À la convergence de taille entre les bovins de l'Aspre del Paradis et ceux de La Draga, s'ajoute la forme évoluée de la cheville osseuse de bélier, manifestement très transformée par rapport à celles qu'on peut observer par exemple dans l'Impressa d'Italie du sud (Vigne et Carrère, inédit) ou dans le Cardial tyrrhénien de Basi (Vigne, 1988). Enfin, bien que peu nombreuses, les données d'âge d'abattage suggèrent assez clairement l'exploitation de productions secondaires, tant pour les bovins que pour les caprinés, fait qui ne se généralise dans le Midi de la France qu'avec la fin du Néolithique ancien et surtout durant le Néolithique moyen (Vigne et Helmer, 1999; Helmer et Vigne, en prép.). Une datation du Cardial récent, de l'Épicardial, voire du Chasséen ne serait donc pas choquante au regard de cette faune.

\section{Les restes carpologiques}

Une première expertise carpologique a pu être entreprise à la faveur des tamisages sous eau effectués sur le terrain par l'équipe de fouille. À cette occasion, un prélèvement de quarante litres environ, provenant de la fosse silo 5, fut traité sur un seul crible de $4 \mathrm{~mm}$. En dépit de l'ouverture importante du tamis, quelques restes carpologiques carbonisés ont pu être recueillis. Il fut alors décidé de procéder à un tamisage plus fin, par flottation manuelle (cribles de 2 et $0,5 \mathrm{~mm}$ ), sur un prélèvement brut. Malheureusement, la quantité de sédiment disponible était assez limitée (10 litres).

Au total, les données enregistrées s'avèrent très restreintes (tabl. 8) et ne doivent pas être considérées comme représentatives des ressources alimentaires végétales des occupants du site. Les restes de céréales sont nettement dominants. Toutefois, ils sont assez mal conservés et généralement fragmentés. L'altération des semences alliée à leur rareté ne permet pas d'atteindre un niveau de détermination précis. Le silo 5 a livré un

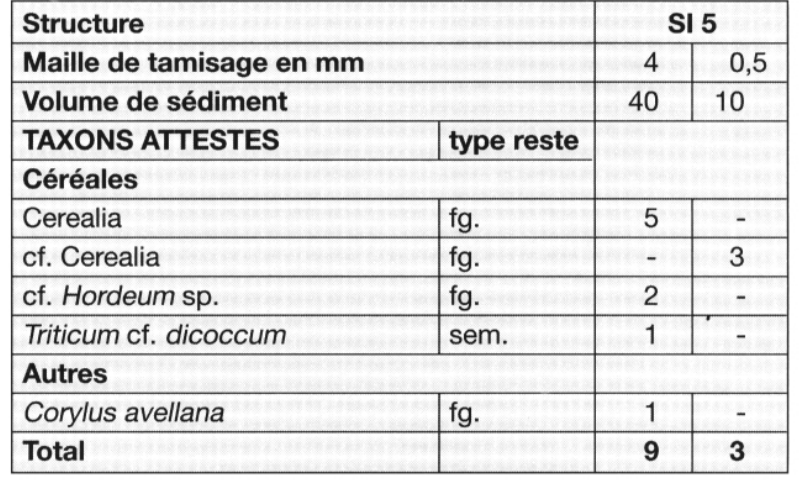

Tabl. 8 - Fosse-silo 5 : restes carpologiques carbonisés.

grain de blé, vraisemblablement d'amidonnier (Triticum cf. dicoccum), ainsi que deux fragments sans doute attribuables à une espèce d'orge (cf. Hordeum sp.). L'amidonnier était jusqu'à une date récente considéré comme n'apparaissant dans l'agriculture du Midi de la France qu'à partir de l'Épicardial (Marinval, 1988). Toutefois, de nouveaux travaux entrepris sur la baume de Fontbrégoua (Var) ont montré la présence de ce blé vêtu, en quantité très limitée cependant, dès la phase ancienne du Cardial (Savard, 2000). D'autre part, l'amidonnier semble jouer un rôle important dans les sites languedociens de faciès ligurien (Marinval, comm. orale). En Espagne, l'espèce apparaît très fréquemment et connaît une bonne représentation dans les sites cardiaux de la Catalogne et du pays valencien, plus particulièrement au cours de la phase ancienne (Buxò i Capdevila, 1993). À la lumière des données espagnoles et des résultats récemment acquis dans le Midi de la France, la présence de l'amidonnier à Corneilla ne semble donc pas surprenante. Il est regrettable que les probables restes d'orge ne puissent être identifiés au niveau variétal. Effectivement, les données carpologiques actuelles enregistrent des différences dans les types d'orges exploités en France méditerranéenne et dans le Levant espagnol au Néolithique ancien. Dans le sud de la France, seule l'orge polystique à grains nus semble présente dans les sites cardiaux (Marinval, 1988). Au sud des Pyrénées, les deux types d'orge polystiques, à grains nus et vêtus, coexistent fréquemment dans les spectres carpologiques (Buxò i Capdevila, 1993).

La flore spontanée est uniquement représentée dans le silo 5 par un fragment de coquille de noisette (Corylus avellana). Celui-ci doit vraisemblablement être mis en relation avec une activité de cueillette.

\section{L’industrie lithique taillée}

Le silo 5 n'a livré que trois pièces se rapportant à l'industrie lithique taillée. On trouve un débris de silex brûlé, un débris de silex blond translucide appartenant peut-être à un outil et un petit fragment mésial de lamelle prismatique, de rythme 2-1-2', à nervures régulières. Celle-ci, en silex blond, présente des retouches irrégulières (accidentelles?). Ces quelques fragments ne suffisent malheureusement pas pour préciser le contexte technique et culturel de l'assemblage du silo 5 . 


\section{Le macro-outillage}

Le silo 5 a livré 10 pièces de macro-outillage (fig. 9). Le peu de pièces entières ( 3 cas sur 10) ne permet pas l'ébauche d'un classement typométrique. On peut néanmoins reconnaître trois groupes principaux :

- les molettes ( 2 pièces, fig. $\left.9, \mathrm{n}^{\circ} 1\right)$,

- les meules actives, dont la taille permet une manipulation facile de la pièce ( 5 pièces, fig. $9, \mathrm{n}^{\circ \mathrm{s}} 2-3$ ),

- et les meules dormantes (4 pièces, fig. $9, \mathrm{n}^{\text {os }} 4-5$ ).

La matière première utilisée pour les dix pièces est le granit à cristaux plus ou moins gros. Il n'existe pas de mise en forme particulière de ces pièces. Les ressources naturelles ont été utilisées telles quelles. L'une des meules dormantes livre une surface légèrement convexe (fig. $9, n^{\circ} 4$ ). Deux des meules actives présentent, sur leur face supérieure, une striation grossière qui pourrait correspondre aux traces d'utilisation. En dehors de ces pièces destinées aux travaux de meunerie, le silo $5 \mathrm{a}$ également livré une dalle de gneiss, de 3,5 cm d'épaisseur pour une longueur conservée de $13 \mathrm{~cm}$. Cette pièce, pourrait correspondre à un fragment du bouchon du silo.

\section{Les données radiométriques}

Deux datations ont été réalisées sur des ossements provenant du silo 5 (tabl. 9). Ces deux mesures sont statistiquement non différentes (Test de T effectué par le logiciel Calib 3.4). Elles situent donc l'occupation du Néolithique ancien de Corneilla del Vercol à la transition du sixième et du cinquième millénaire avant notre ère.

La figure 10 regroupe les datations du Cardial récent et de l'Épicardial du Languedoc occidental et de la province de Gérone. Un récent travail a conduit à proposer un schéma d'évolution du Néolithique ancien de cette zone, en trois grandes phases chrono-culturelles (Manen, 2000a).

La première phase, comprise entre 5750 et 5300 av. J.-C., voit l'implantation des faciès à céramiques imprimées sur les côtes languedociennes et catalanes. Ceux-ci s'expriment au travers de caractéristiques stylistiques variées qui suggèrent la multiplicité de leur origine (Manen, 2000b).

La deuxième phase identifiée, comprise entre 5300 et 5000/4900 av. J.-C., voit l'évolution en parallèle de deux styles céramiques, Cardial récent et Épicardial ancien, dont l'interprétation en termes culturels est la plus probable. Devant l'absence de réelle exclusion géographique, l'explication de cette cohabitation reste délicate.

La troisième et dernière phase chronologique, située entre 5000/4900 et 4500 av. J.-C. voit, au contraire de la précédente, une homogénéisation stylistique de la
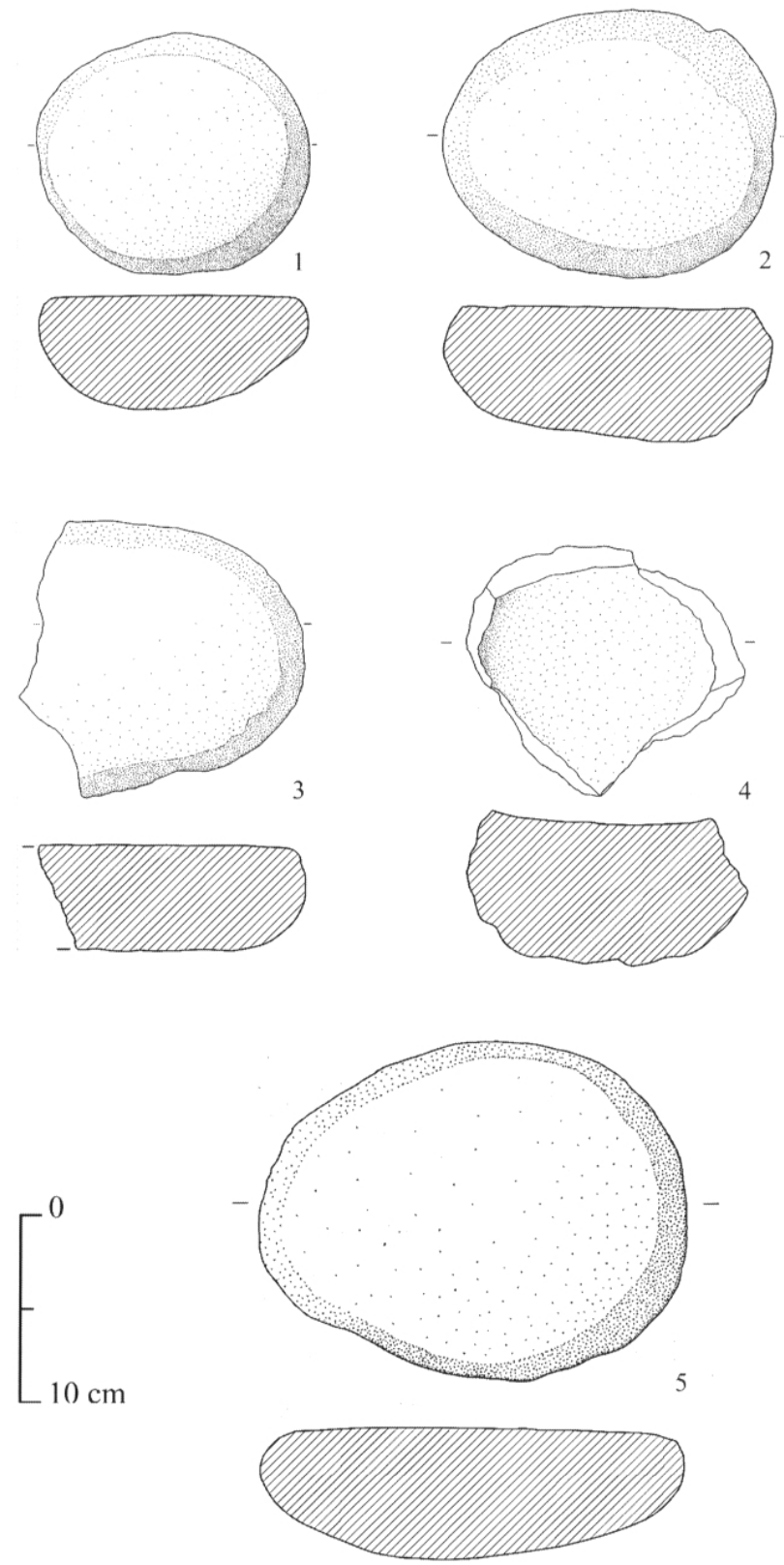

Fig. 9 - Fosse-silo 5 : macro-outillage. 1 : molette; $2-3$ : meule active; 4-5: meule dormante.

décoration céramique. Cette consolidation reste à confirmer par les autres composantes du système technique. On assiste par ailleurs aux prémices de l'installation de réseaux de circulation de certaines matières premières, qui connaîtront leur apogée durant le Chasséen.

Les datations de l'Aspre del Paradis ainsi que les caractéristiques du mobilier céramique et des restes fauniques proposent un rattachement à la deuxième phase chrono-culturelle (Cardial récent/Épicardial ancien).

\begin{tabular}{|l|l|l|l|l|}
\hline Code labo & Matériau daté & Date BP & Calibration à 1 sigma & Calibration à 2 sigma \\
\hline GRA 16273 (Ly 1163) & Ovis : radius droit proximal & $6030 \pm 40 \mathrm{BP}$ & $4960-4800$ av. J.-C. & $5040-4790$ av. J.-C. \\
\hline Ly 10069 & Bos : métacarpe droit proximal & $5915 \pm 50 \mathrm{BP}$ & $4850-4710$ av. J.-C. & $4920-4680$ av. J.-C. \\
\hline
\end{tabular}

Tabl. 9 - Fosse-silo 5 : datations radiocarbones. 
4tmospheric data from Stuiver et al. 1998 ; OxCal v3.5

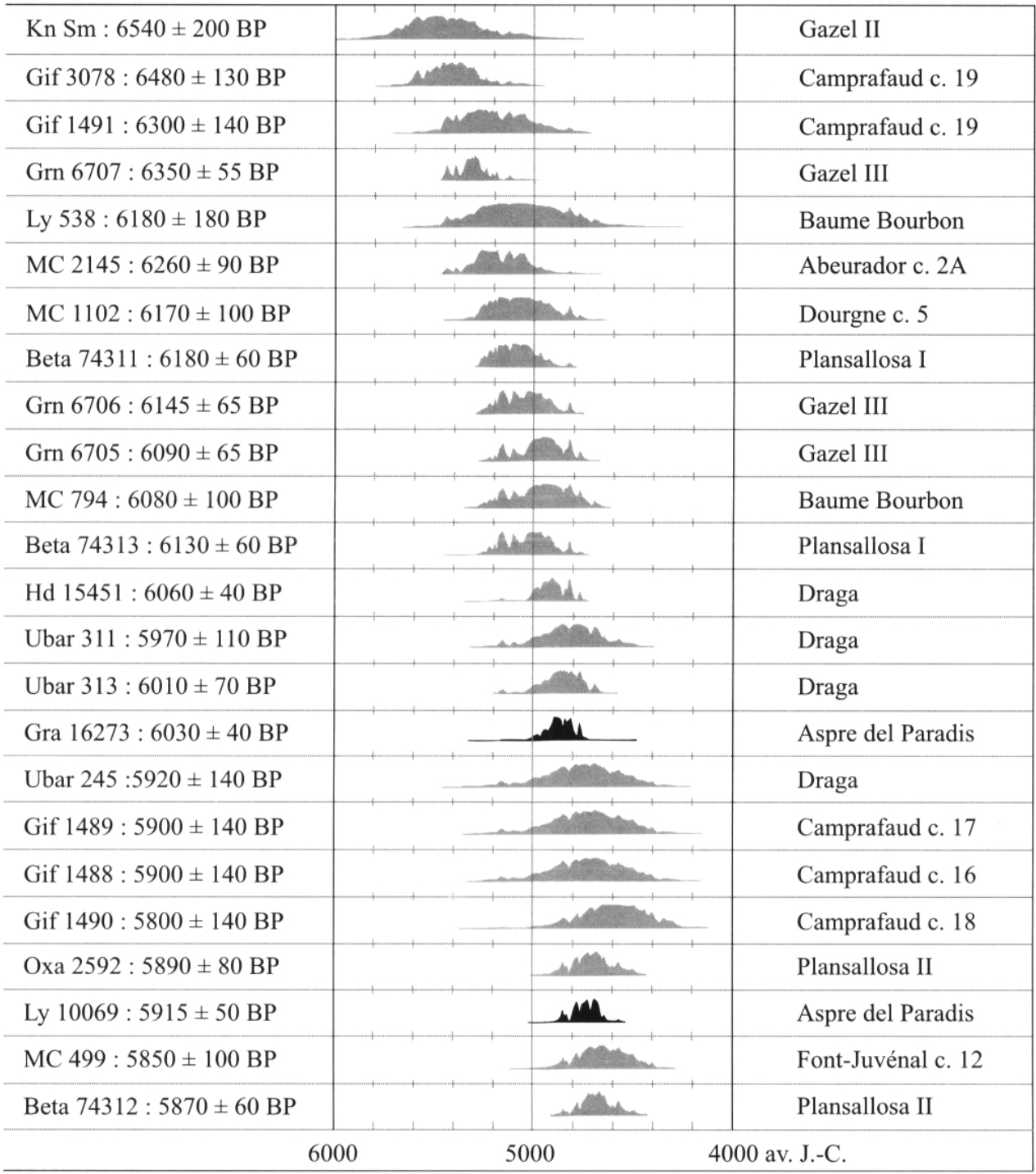

Fig. 10 - Histogrammes de probabilité des datations calibrées du cinquième millénaire av. J.-C.

\section{Le Néolithique final : le silo 6}

\section{La céramique}

La série céramique issue du silo 6 comprend 294 tessons dont la plus grande dimension est supérieure ou égale à $1 \mathrm{~cm}$. Le taux de fragmentation de la série est important. La dimension moyenne des tessons est d'environ $5 \mathrm{~cm}$. Ces fragments se répartissent comme indiqué sur le tableau 10.

Il n'est pas possible de proposer une description de cet ensemble céramique en termes d'individus. C'est pourquoi nous présenterons directement les caractéristiques de la série de manière synthétique.

La quasi-totalité des fragments récoltés présente une pâte à tendance sableuse. On retrouve ainsi les caractéristiques de la céramique du Néolithique ancien. De même, le dégraissant est majoritairement composé de quartz et de calcite. Le mica est également bien représenté. Le dégraissant est généralement assez fin, bien qu'il existe différents cas de figures suivant la taille des récipients. Certaines pâtes présentent un aspect vacuolé qui peut suggérer l'emploi de dégraissant en matière végétale.

L'observation des traces de façonnage et de finition se heurte à la fragmentation de la série. L'épaisseur moyenne des tessons est de $0,8 \mathrm{~cm}$ pour un écart-type de 0,3. Les épaisseurs minimales et maximales correspondent respectivement à 0,3 et $2,1 \mathrm{~cm}$. Cependant, la majorité des épaisseurs est comprise entre 0,5 et $1 \mathrm{~cm}$.

\begin{tabular}{|l|c|}
\hline TYPES DE RESTES & $\begin{array}{c}\text { Nbre } \\
\text { de restes }\end{array}$ \\
\hline Indéterminé & 259 \\
\hline Bord & 24 \\
\hline Bord et préhension & 5 \\
\hline Préhension & 6 \\
\hline Total & 294 \\
\hline
\end{tabular}

Tabl. 10 - Fosse-silo 6 : distribution des différents types de tessons en nombre de restes. Indéterminé = position inconnue sur le vase. 
Il est ainsi possible de distinguer différentes classes de récipients que l'on ne peut cependant pas systématiquement rattacher à des formes précises. Les traces de façonnage sont rares. La technique du montage au colombin est cependant attestée par la présence de fractures en gouttière. Quelques fragments attestent de la pratique du lissage et du brunissage. Les atmosphères de cuisson, oxydante ou réductrice, sont utilisées sans préférence particulière. Les vases reconstituables montrent par ailleurs que les parties d'une poterie ont pu être exposées de manière différente à l'influence de l'oxygène et des gaz de combustion. Les indications livrées par les fragments sont donc toutes relatives.
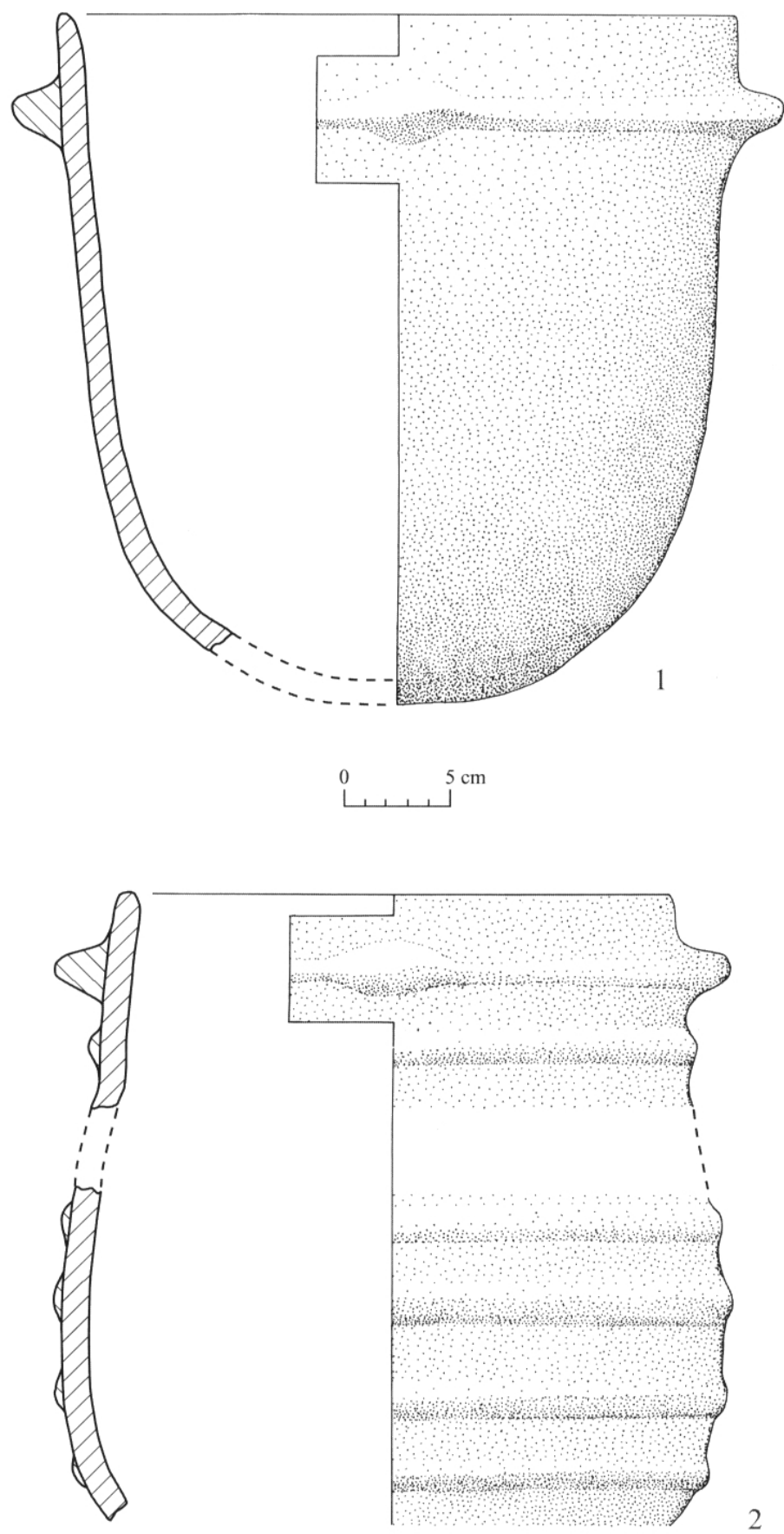

Fig. 11 - Fosse-silo 6 : vases de stockage décorés de cordons lisses simples ou multiples superposés.
L'essentiel des gammes classiques de couleur est représenté, avec une préférence pour les tons brun-rouge. L'observation des couleurs des surfaces internes et externes et du cœur des fragments permet d'observer que $80 \%$ des cuissons, en atmosphère réductrice ou oxydante, ont été complètes.

Du point de vue de la morphologie et de la décoration des vases, il est possible de distinguer plusieurs types, malgré la forte fragmentation. La série est principalement caractérisée par la présence de jarres cylindriques décorées d'un ou plusieurs cordons horizontaux parallèles (fig. 11). Deux vases de ce type sont graphiquement reconstituables tandis que 58 fragments présentent les mêmes caractéristiques. Sur les deux vases, une large languette proéminente, située sous le bord, est intégrée au décor de cordon lisse. On retrouve cette même association sur 4 autres fragments (fig. 12, $\mathrm{n}^{\text {os }} 1$ à 3). Dans une catégorie de vases moins volumineux, on peut observer la présence de marmites et de bols dont il n'est pas possible de restituer le profil (fig. 12, $\mathrm{n}^{\circ} 7$ et fig. 13). Ces vases ne portent aucun décor. Notons enfin la présence d'un récipient légèrement fermé à profil composite (cran, fig. 13, n 7 ). Les éléments de préhension (fig. 13) sont représentés par des languettes ( 5 pièces), des mamelons ( 5 pièces) et un téton.

L'essentiel des caractéristiques morphologiques de la céramique du silo 6 se résume donc par la présence de : - vases volumineux de type jarres munis de languettes de préhension diamétralement opposées et décorés d'un ou plusieurs cordons lisses (fig. 11); le vase $n^{\circ} 1$ possède un volume estimé de près de 14 litres;

- vases de plus faible contenance, plus soignés, à profil généralement continu, non décorés et portant parfois languette ou téton (fig. 12 et 13); une série de bord vient confirmer la présence de petits vases (fig. 13); - décors principalement réalisés à base de cordons lisses, unique ou superposés, assez irréguliers. On notera également la présence de deux petits tessons décorés d'impressions. Le premier décor est assez érodé mais il est possible d'identifier des impressions à la cordelette large disposées en chevron (fig. 14, $\left.\mathrm{n}^{\circ} 1\right)$. Le second tesson présente un faible cordon digité (fig. 14, $\mathrm{n}^{\circ} 2$ ).

Les caractéristiques de cette série céramique nous permettent de la rattacher au Néolithique final (Gascó et Gutherz, 1986; Gutherz et Jallot, 1995). Cette période est caractérisée, en Midi méditerranéen, par l'éclosion de faciès régionaux aux caractères bien typés : Courronnien, Saint-Ponien, Ferrières, Fontbouisse et Vérazien. Ces différents faciès présentent des aires de répartition géographique particulières qui se chevauchent parfois. Les caractéristiques de la céramique du silo 6 de l'Aspre del Paradis rappellent celles du faciès SaintPonien défini par Gabriel Rodriguez (1968) et se développant dans la Montagne noire. Ce faciès semble être assimilable à celui du Vérazien ancien dont l'aire d'extension est davantage centrée sur le bassin de l'Aude et le Roussillon. Les datations disponibles permettent de caler le Saint-Ponien et le Vérazien ancien entre 

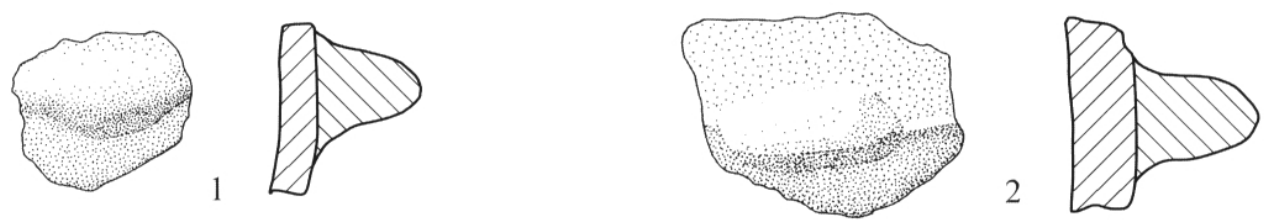

0 $3 \mathrm{~cm}$
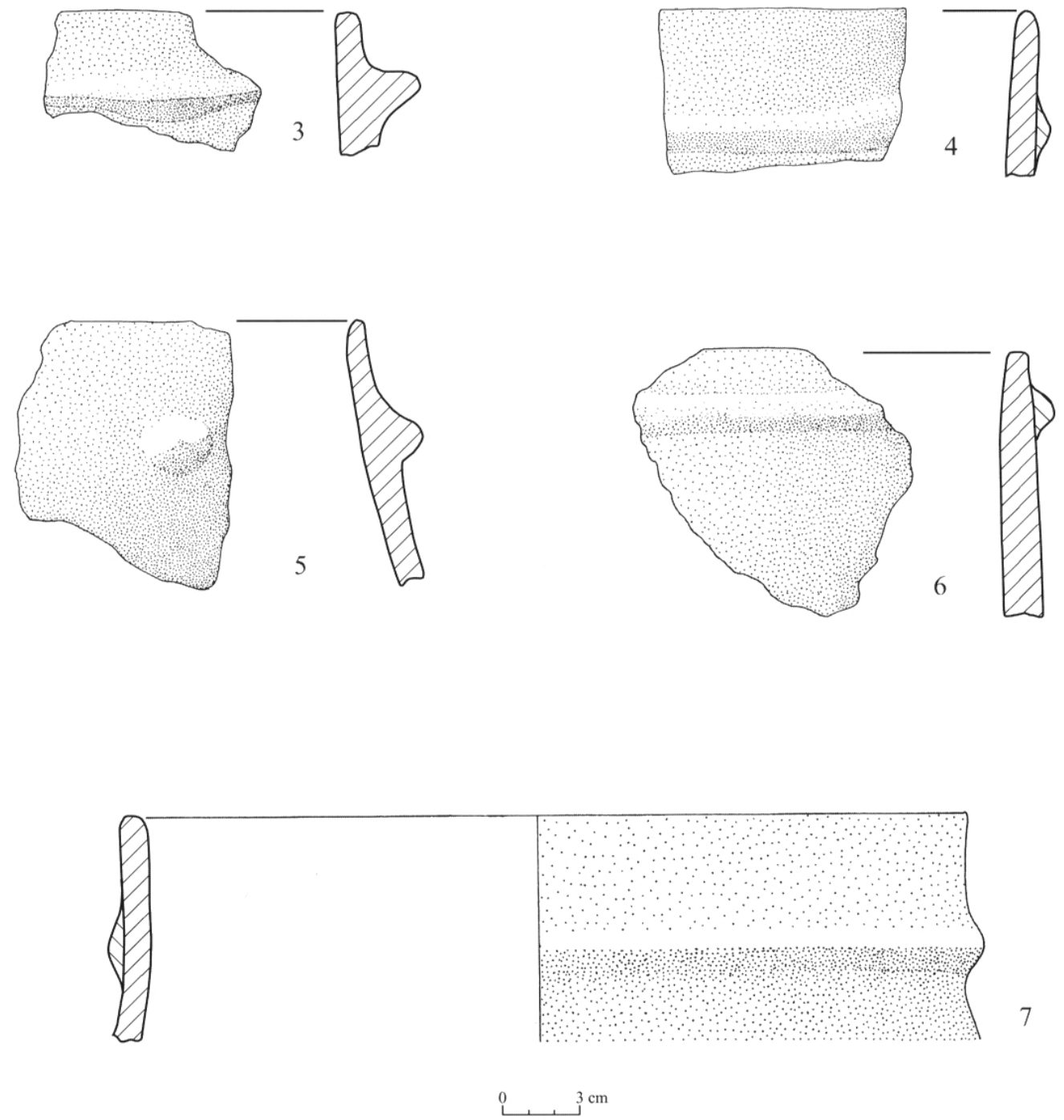

Fig. 12 - Fosse-silo 6 : éléments de préhension et décor de cordons lisses. 1-2 : languettes; 3 : languette prolongée par un cordon lisse; 4 et 6-7 : cordons lisses disposés sous le bord; 5 : téton disposé sous le bord.

3500 et 3000 avant notre ère (Gutherz et Jallot, 1995; Vaquer, 1998). Du point de vue de la céramique, on trouve plusieurs types morphologiques de récipients : petits vases s'inscrivant dans une tradition chasséenne (écuelle à carène, gobelets, coupes et bols), vases de dimensions moyennes ovoïdes, cylindriques ou tulipiformes portant cordon(s) lisse(s) et/ou préhension en languette et grandes jarres à cordons lisses multiples. Si l'on excepte les deux fragments décorés (fig. 11), on retrouve ici l'ensemble des caractéristiques de la céramique du silo 6 de l'Aspre del Paradis.

Le tesson décoré d'un léger cordon imprimé est trop ubiquiste pour que l'on tente tout rattachement culturel. Le petit fragment présentant un décor de chevrons emboîtés probablement réalisé à la cordelette rappelle certains éléments découverts dans les niveaux de la fin du Néolithique de Font-Juvénal, Conques-sur-Orbiel, Aude (Guilaine et al., 1980 et Guilaine comm. orale). 

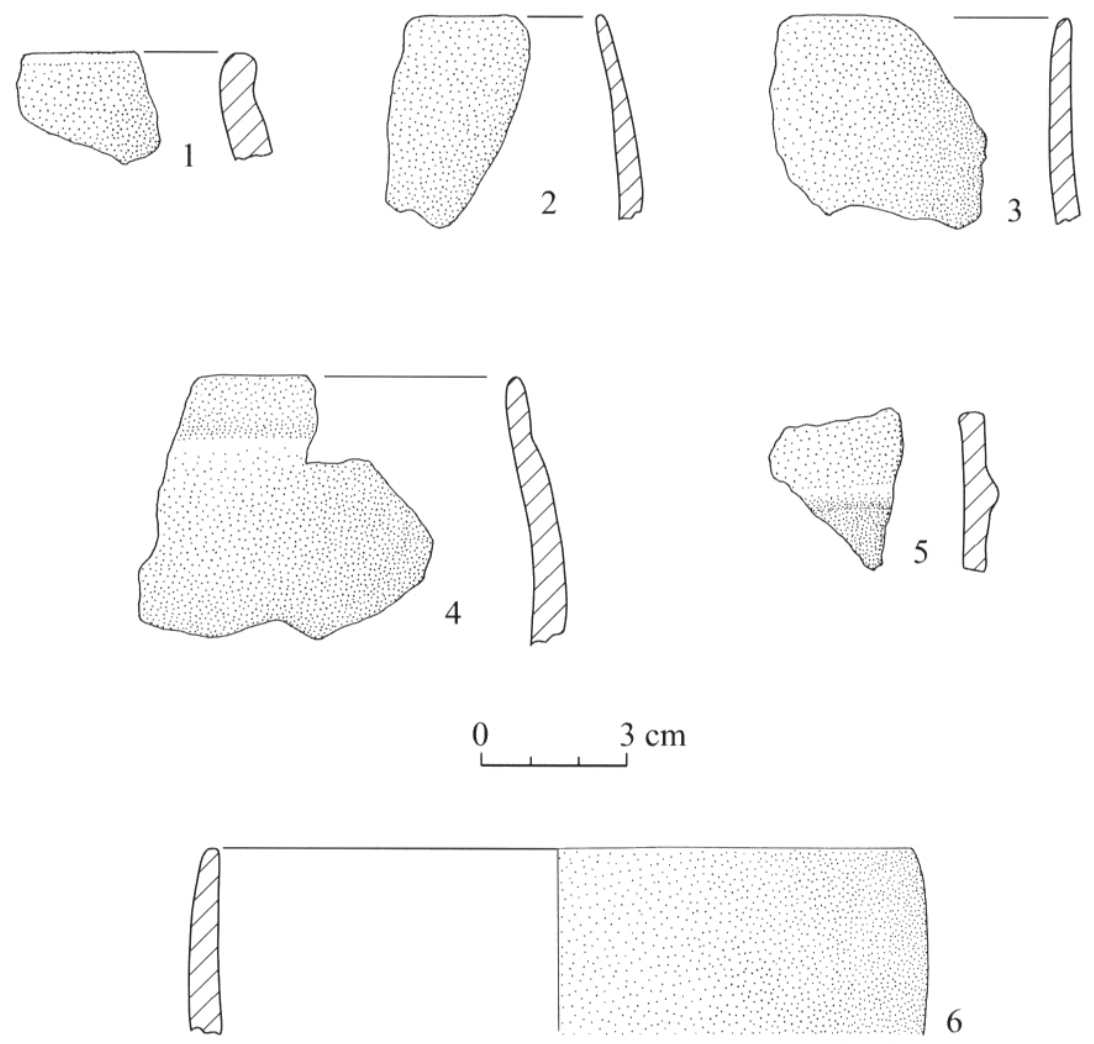

Fig. 13 - Fosse-silo 6 : vases de petite dimension. 1-3 : bords; 4 : bol à cran; 5 : décor plastique ; $6:$ bol probablement hémisphérique.

Ces éléments apparaissent dans les couches 3 et $2 \mathrm{c}$ aux côtés de témoins véraziens. Ils sont décrits comme "des restes de récipients (en cloche?) portant une ornementation "cordée" qui ne paraissent pas se rattacher au complexe campaniforme à décor de cordelette " (Guilaine et al., 1980, p. 14). Il est vrai que le décor de cordelette du Campaniforme languedocien est très fin, environ $1 \mathrm{~mm}$ de diamètre (Salanova, 2000). Ces éléments "de type cordé" sont associés à Font-Juvénal c. 3 avec des jarres comportant des tétons, des cordons lisses superposés ou un cordon unique disposé sous le bord. Dans la couche 2c, on voit l'apparition de mamelons superposés, absents de la série de l'Aspre del Paradis. La couche 3 de Font-Juvénal (Conques-surOrbiel, Aude) offre donc un parallèle intéressant. Elle est attribuée à un Vérazien vrai en concordance avec le Ferrières et le "Cordé" (Guilaine et al., 1980, p. 16).
De nombreux points communs existent entre notre série et celles du Vérazien classique : récipients de forme sphérique ou cylindrique à fond rond, coexistence de diverses tailles (de la vaisselle courante de petite dimension aux vases de stockage dont l'encombrement est très important), préhensions en tétons, languettes ou mamelons (Vaquer, 1980). Du point de vue de la décoration, on retrouve les cordons lisses uniques ou superposés généralement disposés sur les grands vases cylindriques. Les éléments de préhensions sont fréquemment associés aux cordons lisses (Gascó et Gutherz, 1986). Cependant, dans le cas de l'attribution de la série au Vérazien, il faut alors noter l'absence d'une des ses caractéristiques typiques, celles des éléments de préhensions superposés. Cette absence pourrait être mise sur le compte de la non représentativité de l'échantillon. On remarquera pour terminer que l'assemblage de la
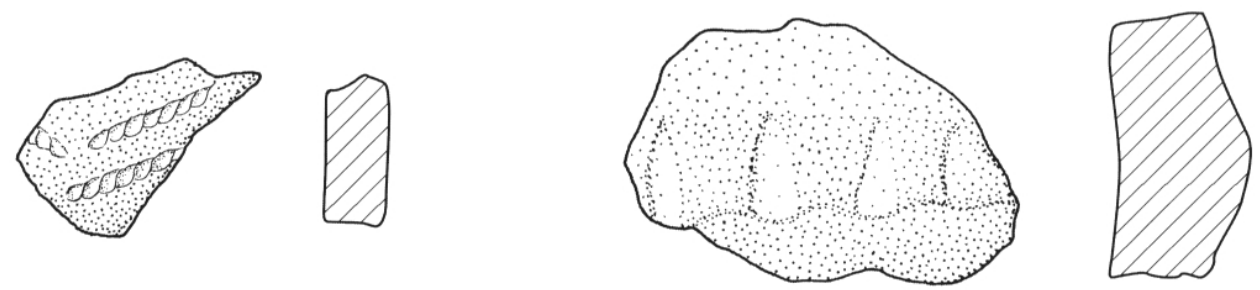

0 $3 \mathrm{~cm}$

Fig. 14 - Fosse-silo 6 : fragments décorés d'impressions. 1 : impressions à la cordelette disposées en chevrons ; 2 : impressions allongées disposées sur un léger cordon. 
grotte de Chincholle (Camps-sur-l'Agly, Aude) fournit un élément de comparaison remarquable. Cet assemblage a été attribué au Vérazien ancien (ou SaintPonien) sur la base des caractéristiques stylistiques de la céramique et notamment de l'absence de préhensions superposées (Treinen-Claustre, 1982).

\section{Les restes fauniques et humains}

Le silo 6 n'a livré que onze restes fauniques déterminés. Deux d'entre eux, rapportés à des andouillers de cerfs, ne témoignent pas de la consommation de l'animal. Les 9 autres renvoient au porc (maxillaire d'un animal tué entre deux et quatre ans) et surtout au bœuf, la moitié des ossements de grands ruminants ayant pu être rapportée sans ambiguïté à cette espèce domestique (tabl. 11). L'assemblage est trop restreint pour tirer la moindre information de ce spectre taxinomique. Les seules données remarquables concernent les dimensions des os de bovins ${ }^{1}$ qui sont sensiblement inférieures à celles du silo 5 (fig. 15), en restant toutefois plus importantes que celles de proches sites de l'Âge du Bronze tels que Carcassonne-Carsac (Aude; Vigne, 1986 et 1996). Compte tenu de la décroissance progressive de la taille des bovins domestiques du Néolithique ancien à l'Âge du Fer, cette situation métrique désigne une phase récente ou finale du Néolithique.

À ces restes de faunes s'ajoute un fragment de diaphyse de tibia droit d'un sujet humain adulte.

\begin{tabular}{|l|l|c|c|}
\hline \multicolumn{2}{|l|}{ Taxons } & NR & NMI \\
\hline Porc & Sus scrofa domesticus & 1 & 1 \\
\hline Bœuf domestique & Bos taurus & 4 & 1 \\
\hline Grands ruminants & Ruminantia & 4 & 1 \\
\hline & TOTAL Déterminés & 9 & 3 \\
\hline Cerf élaphe & Cervus elaphus & 2 & \\
\hline
\end{tabular}

Tabl. 11 - Nature et fréquence des mammifères de la fosse-silo 6 de l'Aspre del Paradis. NR, Nombre de Restes; NMI, Nombre Minimal d'Individus de fréquence.

\section{Industrie en matière dure animale}

L'industrie osseuse est représentée par un outil perforant de type poinçon, réalisé sur un métacarpe de bœuf. En dépit du caractère anecdotique de cette pièce, on notera que l'industrie sur os est très développée dans le Saint-Ponien.

\section{Les restes carpologiques}

Le processus d'acquisition des données est exactement similaire à celui mis en œuvre pour la fosse-silo $5 \mathrm{du}$ Néolithique ancien. Un premier prélèvement de quarante litres environ a été tamisé lors des fouilles sur un crible de $4 \mathrm{~mm}$, puis une flottation manuelle sur tamis de 2 et $0,5 \mathrm{~mm}$ a porté sur 10 litres de sédiment.

Le matériel recueilli est également comparable à celui de la première fosse : on observe une très faible concentration de restes dans le sédiment, une fragmentation importante et une altération des surfaces assez prononcée. Le corpus de carporestes est également dominé par les céréales (tabl. 12). Seule la présence de l'orge peut être affirmée (Hordeum sp.), mais l'érosion des deux grains et des fragments observés ne permet pas de préciser s'il s'agit d'une forme à grains nus ou à grains vêtus. Les deux types sont présents à cette époque dans le Midi de la France.

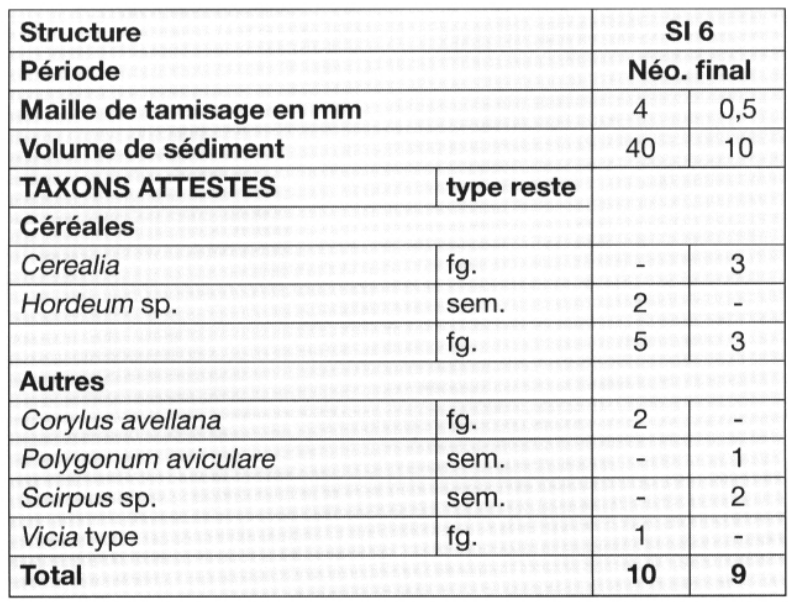

Tabl. 12 - Fosse-silo 6 : restes carpologiques carbonisés.

Le compartiment des plantes sauvages enregistre la présence de deux fragments de coquilles de noisettes (Corylus avellana), résultat probable d'une cueillette alimentaire, et de semences de renouée des oiseaux (Polygonum aviculare) et de scirpe (Scirpus sp.). La renouée des oiseaux est une plante rudérale, fréquente aux abords des lieux habités, mais qui peut également constituer une mauvaise herbe des cultures. En revanche, les scirpes sont des plantes de lieux humides, dont

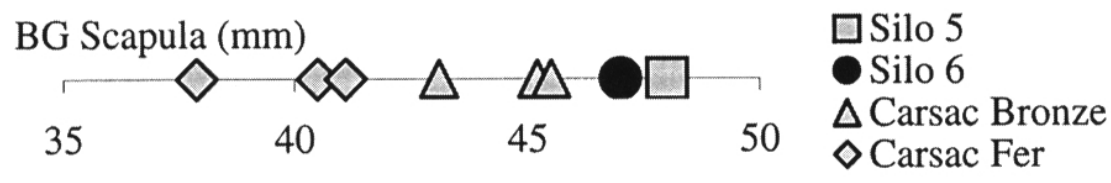

Bd Métacarpe (mm)

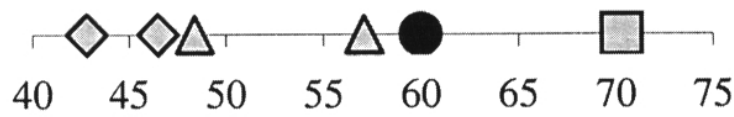

Fig. 15 - Comparaison des dimensions (selon Driesch, 1976) d'une scapula et d'un métacarpe de bœuf du silo 6 de l'Aspre del Paradis avec celles de leurs homologues du silo 5 du même site et de l'Âge du Bronze final et du Fer de Carsac (Aude; Vigne et coll., 1986). 


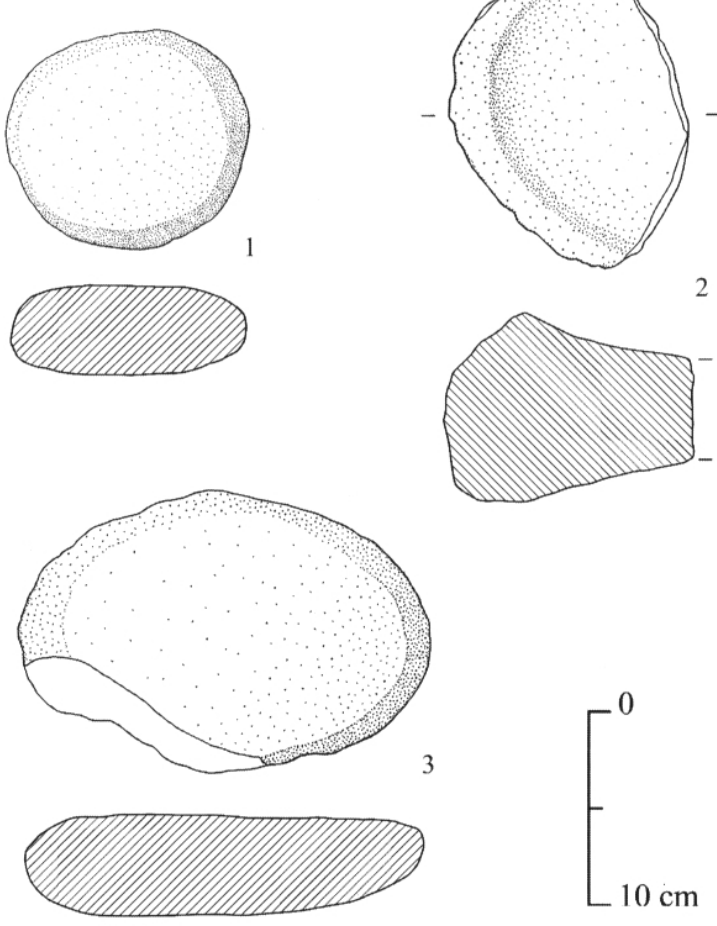

Fig. 16 - Fosse-silo 6 : macro-outillage. 1 : molette; 2 : meule dormante; 3 : meule active.

la croissance n'est pas particulièrement favorisée par la présence humaine.

\section{Le macro-outillage}

Le silo 6 a livré 8 pièces de macro-outillage correspondant aux types suivants :

- molette ( 2 pièces de forme circulaire ou allongée, fig. $\left.16, \mathrm{n}^{\circ} 1\right)$,

- meule active ( 1 pièce de forme ovale, fig. $16, \mathrm{n}^{\circ} 3$ ),

- et meule dormante $(5$ pièces dont une seule entière et de forme oblongue).

Les matières premières utilisées pour les huit pièces sont le granit ou micro-granit (5 pièces) et le gneiss granitoïque ( 3 pièces). Comme pour le matériel du silo 5, il n'existe pas de mise en forme particulière de ces pièces. L'une des meules dormantes a été utilisée sur les deux faces qui présentent un profil convexe (fig. 12, $\mathrm{n}^{\circ} 2$ ). Deux autres meules montrent des surfaces actives totalement planes (fig. 12, $n^{\circ} 3$ ). Enfin, deux pièces livrent des traces de feu qui n'ont pas forcément été volontaires.

\section{Le torchis}

Les restes de torchis représentent en poids $11523 \mathrm{~g}$. Le procédé d'étude de ces restes repose sur la reconnaissance de forme particulière et sur les modalités de cuisson subies (Chazelle et Poupet, 1985; Vaquer, 1986; Tasca, 1998). De cette manière, trois principaux types de restes peuvent être distingués :
- les mottes informes représentant 3288 g soit 28,5\% de la série;

- les restes possédant deux faces oxydées clairement identifiables représentant 4921 g soit $42,8 \%$ de la série;

- et les restes dont une seule face oxydée est nettement visible représentant 3314 g soit $28,7 \%$ de la série.

À l'intérieur de ces trois grandes catégories de restes, il est possible d'affiner la description et de proposer quelques interprétations de la nature de ces restes.

Parmi les fragments appartenant à la catégorie des mottes informes, quelques blocs montrent des traces assez nettes d'empreintes. Ces blocs sont cependant très peu nombreux ( $\mathrm{NR}=4$, soit $88 \mathrm{~g})$. Ils se reconnaissent par la présence d'une zone incurvée, plus régulière par rapport à l'ensemble de la pièce. Ces traces correspondent à l'application du torchis sur un objet de section plus ou moins circulaire, de taille assez modeste. La distinction entre une empreinte de doigt ou de branchage n'est pas évidente mais il semble, après observation à la loupe binoculaire, que ces empreintes correspondent plutôt à celles de branchages. Les autres restes de mottes informes, sans traces particulières, sont de modules très variés (gros blocs à petits fragments) et n'offrent pas de renseignements particuliers sur l'utilisation du torchis. Il est étonnant d'observer que les empreintes de clayonnage sont rares sur ces restes alors que, le plus souvent, le torchis intervient en garnissage sur une armature végétale.

La deuxième catégorie identifiée est caractérisée par des restes à faces planes et plus ou moins lissées. Le torchis prend alors l'aspect de la céramique mais dans des proportions plus grossières. Les restes de ce type sont nombreux (NR = 94 soit $4921 \mathrm{~g}$ ). L'épaisseur moyenne de ces fragments est de $2,3 \mathrm{~cm}$. Elle varie entre 1,3 et $4 \mathrm{~cm}$. L'ensemble de ces restes présente des surfaces planes, toutes deux de couleur rouge-orange. Ces caractéristiques suggèrent la présence de réels récipients de torchis. Ceux-ci étaient probablement montés par grosses plaques successives. D'autres éléments étayent cette hypothèse. Il s'agit d'une part de la reconnaissance de fragments de bords ( $\mathrm{NR}=12$ soit $486 \mathrm{~g}$ ) et d'autre part de la présence d'un fond plat. Les bords sont assez grossiers. L'épaisseur de ceux-ci est comprise entre 1,5 et $4 \mathrm{~cm}$. Ces fragments se distinguent clairement de ceux de la céramique proprement dite par leur aspect (absence de dégraissant, texture particulière...). Il est possible d'observer, sur les fragments de parois (dans 6 cas au moins), des traces de lissages (traces incurvées régulières) visibles sur les deux faces. On notera, pour terminer, que ces fragments, appartenant à un ou plusieurs vases, sont particulièrement bien représentés puisqu'ils constituent près de $43 \%$ de la série. Ces vases ont certainement cuit lors d'un incendie.

La troisième catégorie correspond à celle des gros blocs dont une face est plane, oxydée tandis que l'autre face, de couleur noire-grise, est irrégulière $(\mathrm{NR}=72$ et poids $=3314 \mathrm{~g}$ ). Ces restes peuvent être interprétés comme appartenant à un four ou à un enduit déposé sur la paroi d'un silo dont le contenu a brûlé (la face lisse 
oxydée correspond à celle plaquée sur le silo). Le peu d'éléments de forme et l'importante fragmentation de ces pièces interdisent de conclure. Dans cette même catégorie, quelques pièces sont particulièrement fines. Elles constituent peut-être un revêtement particulier $(\mathrm{NR}=14)$. Cette catégorie peut également appartenir à des plaques de foyer, plus ou moins épaisses, destinées au grillage. On notera enfin la présence de deux blocs portant des incisions nettes et profondes, parallèles ou concentriques.

Les caractéristiques des torchis découverts dans le silo 6 sont très variées et plaident en faveur d'un dépôt secondaire de ceux-ci. En effet, on retrouve associés des fragments ayant été utilisés dans des buts très différents, tels que le façonnage de vase (probablement de stockage), l'enduit de fosse ou la cuisson. L'utilisation du torchis pour la construction proprement dite n'est pas réellement attestée. Pour résumer, on retrouve des fragments de vases en torchis ( 2 surfaces planes oxydées), des mottes informes dont la nature est difficilement interprétables et des pièces appartenant probablement à des enduits de silos (1 face plane oxydée et l'autre informe et de couleur sombre). Ces torchis témoignent également d'une occupation du site relativement établie dont malheureusement aucun autre reste n'a pu être repéré. Enfin, la découverte de ce type de reste est en accord avec l'attribution du silo 6 au Néolithique récent-final (Gascó, 1980). En effet, comme l'Aspre del Paradis, les sites de plein air du Néolithique final livrent fréquemment des restes de torchis (la Bouscade, Valentines, le Longuet, El Coll, Saint-Jean-de-Cas ou les Garrigues Blanches).

\section{CONCLUSIONS}

L'Aspre del Paradis offre divers témoignages se rapportant au Néolithique ancien et final. La plaine du Roussillon fournit une concentration importante de sites néolithiques notamment entre les vallées du Tech et de l'Agly (Vignaud, 1990 et 1992). Ces sites appartiennent fréquemment au Néolithique moyen et final alors que le Néolithique ancien n'est que très peu représenté. L'Aspre del Paradis apporte ainsi un nouveau témoignage, bien que limité, de l'occupation de la zone, à la charnière des $5^{\mathrm{e}}$ et $6^{\mathrm{e}}$ millénaires avant notre ère. Malgré le caractère réduit des échantillons disponibles, il est possible de discuter de la nature et du contexte chronoculturel et économique de chaque occupation.

Le silo 5 fait référence à une occupation de plein air du Néolithique ancien. Dans la zone qui nous occupe, et dans tout le Midi méditerranéen, ce type d'établissement est très peu documenté, les principales trouvailles se faisant en grotte ou abri. La découverte du silo 5 suggère l'existence d'un habitat aujourd'hui disparu. Ce fait est assez fréquent (Pont de Roque-Haute dans l'Hérault, Font del Ros, Can Soldevila IV ou Can Banús dans la province de Barcelone) et pourrait être imputable aux problèmes taphonomiques ainsi qu'à la faiblesse des traces laissées par les constructions de cette époque. Le caractère varié des artefacts recueillis laisse pourtant penser que l'occupation du site fut plus que ponctuelle (abondance du macro-outillage, pratique de l'élevage bovin par exemple). La diversité du mobilier récolté témoigne de multiples activités domestiques telles que la boucherie, la mouture et le stockage. L'observation de la nature des pâtes et du dégraissant suggère une fabrication locale de la céramique en raison de la proximité et la richesse des ressources. L'alimentation carnée semble dominée par l'élevage mixte de bovins et de moutons mais la chasse n'est pas ignorée. De même, l'alimentation végétale semble concilier la pratique de l'agriculture (céréales) et de la cueillette. La diversité des moyens de subsistance est un trait typique du Néolithique ancien cardial et épicardial du sud de la France. Si l'on s'attache à des questions chronoculturelles, on peut au préalable remarquer que les caractéristiques de la céramique de l'Aspre del Paradis sont plus particulièrement représentatives d'une phase évoluée du Néolithique ancien (Cardial récent/ Épicardial ancien). Cette attribution est confirmée par les restes fauniques et par les données radiométriques. Le silo 6, relatif au Néolithique final, présente également une grande variété d'artefacts. L'utilisation des ressources destinées à la fabrication des céramiques semble identique à celle du Néolithique ancien. Au-delà des quelques éléments témoignant de l'utilisation d'animaux domestiques et de plantes cultivées et de la pratique de la cueillette, la découverte d'abondants restes de torchis permet de supposer l'existence d'un établissement structuré où différentes activités domestiques telles que le stockage et la cuisson étaient pratiquées. D'un point de vue chronoculturel, le doute subsiste. La faiblesse numérique de l'échantillon céramique ne permet pas de trancher entre une attribution au SaintPonien (Vérazien ancien) ou au Vérazien classique.

\section{Remerciements :}

Nous tenons à remercier C.-A. de Chazelles pour son aide dans l'étude des torchis, S. Grouard pour la détermination de l'ichtyofaune et J. Guilaine pour le financement des deux datations.

\section{NOTES}

(1) Scapula : $\mathrm{GLP}=54,7 ; \mathrm{BG}=47,0 ; \mathrm{SLC}=48,8$. Métacarpe : $\mathrm{Dp}=$ 33,$1 ; \mathrm{Bd}=60,0 ; \mathrm{Dd}=31,0$ (code des mesures selon Driesch, 1976). 


\section{RÉFÉRENCES BIBLIOGRAPHIQUES}

ABELANET J. (1980) - Stations du Néolithique final du type de Véraza en Roussillon, in J. GUILAINE dir., Le groupe de Véraza et la fin des temps néolithiques dans le sud de la France et la Catalogne, Colloque (Narbonne, 1977), Éd. du CNRS, Paris, p. 55-60.

BAILLS H. (1991) - Le Néolithique des Pyrénées roussillonnaises, Toulouse, EHESS (Thèse de doctorat, non publiée), 380 p.

BAILON S. (1999) - Différenciation ostéologique des anoures (Amphibia, Anura) de France, in J. DESSE, N. DESSE-BERSET dir., Fiches d'ostéologie animale pour l'archéologie, Série C, Varia, I, Antibes, APDCA, $38 \mathrm{p}$.

BARNETT W.K. (1989) - The production and distribution of Early Neolithic Pottery in the Aude Valley, France, Ann Arbor, University Microfilm International, $545 \mathrm{p}$.

BINDER D. (1991) - Une économie de chasse au Néolithique ancien : la grotte Lombard à Saint-Vallier-de-Thiey (Alpes-Maritimes), Paris, CNRS, Monographie du CRA, 5, 244 p.

BINDER D., COURTIN J. (1986) - Les styles céramiques du Néolithique ancien provençal : nouvelles migraines taxinomiques? in J.-P. DEMOULE, J. GUILAINE dir., Le Néolithique de la France : hommage à Gérard Bailloud, Paris, Picard, p. 83-94.

BOESSNECK J., MÜLLER H.-H., TEICHERT M. (1964) - Osteologische Unterscheidungsmerkmale zwischen Schaf (Ovis aries Linné) und Ziege (Capra hircus Linné), Kühn Archiv, 78 (1-2), p. 1-129.

BOSCH I LLORET Á. (1991) - El Neolitic antic al NE de Catalunya. Barcelona, Bellaterra, Universitat Autònoma, Facultat de Filosofia, (Thèse de doctorat, non publiée), $687 \mathrm{p}$.

BOSCH Á., BUXÒ R., CHINCHILLA J., SAÑA M., TARRÚS J. (1999) - La Draga (Banyoles) et le Néolithique ancien de la Catalogne, in J. VAQUER dir., Le Néolithique du Nord-Ouest méditerranéen, Congrès préhistorique de France, XXIV (Caracassonne, septembre 1994), Joué-lès-Tours, Société Préhistorique Française, p. $195-210$

BOSCH Á., BUXÒ R., PALOMO A., BUCH M., MATEU J., TABANERO E., CASADEVALL J. (1998) - El Poblat neolitic de Plansallosa. L'explotacio del territori dels primers agricultors-ramaders de l'alta Garrotxa, La Garrotxa, Museu Comarcal, (Publicacions eventuals d'arqueologia de La Garrotxa, 5), 116 p.

BUXÒ I CAPDEVILA R. (1993) - Des semences et des fruits. Cueillette et agriculture en France et en Espagne méditerranéennes du Néolithique à l'Âge du Fer, Montpellier, Université de Montpellier II (Thèse de doctorat, non publiée), 2 vol., 634 p.

CHAZELLE C.-A. de, POUPET P. (1985) - La fouille des structures de terre crue : définitions et difficultés, Aquitania, 3, p. 149-160.

CLAUSTRE F., VAQUER J. (1995) - Grotte ou plein-air : acquis et perspectives pour le Néolithique nord-pyrénéen, in : Cultures i medi de la prehistoria a l'edat mitjana, Colloqui internacional d'arqueologia, 10 (Puigcerdà, 1994), Homenatge al Professor Jean Guilaine, Puigcerdà i Andorra, Institut d'Estudis Ceretans, p. 221-239.

CLUTTON-BROCK J., DENNIS-BRYAN K., ARMITAGE P.L. JEWELL P.A. (1990) - Osteology of the Soay Sheep, Bull. British Mus. Nat Hist. (Zool.), 56 (1), p. 1-56.

DRIESCH A. von den. (1976) - A guide to the measurement of animal bones from archaeological sites, Cambridge-Mass., Peabody museum Bulletins, ${ }^{\circ} 1,137 \mathrm{p}$.

DUCOS P. (1968) - L'origine des animaux domestiques en Palestine, Bordeaux, institut de Préhistoire de l'Université (Mémoire, 6), 208 p.

GASC J.-P. dir. (1997) - Atlas of amphibians and reptiles in Europe, Paris, Muséum nat. Hist. nat., p. 108-110.

GASCÓ J. (1980) - Les structures d'habitat de plein air du groupe de Véraza, in J. GUILAINE dir., Le groupe de Véraza et la fin des temps néolithiques dans le sud de la France et la Catalogne, Colloque (Narbonne, 1977), Éd. du CNRS, Paris, p. 103-108.
GASCÓ J., GUTHERZ X. (1986) - Origine et structure du Néolithique final en Languedoc méditerranéen : la céramique, in J.-P. DEMOULE, J. GUILAINE dir., Le Néolithique de la France : hommage à Gérard Bailloud, Paris, Picard, p. 379-390.

GUILAINE J. (1970) - Recherches de Préhistoire récente en Languedoc occidental et Roussillon. Campagne de recherche 1969. La grotte Gazel à Sallèles-Cabardès (Aude), Cahiers Ligures de Préhistoire et d'Archéologie, 19, p. 149-155.

GUILAINE J. (1980) - Le groupe de Veraza et la fin des temps néolithiques en Languedoc et Catalogne, in J. GUILAINE dir., Le groupe de Véraza et la fin des temps néolithiques dans le sud de la France et la Catalogne, Colloque (Narbonne, 1977), Éd. du CNRS, Paris, p. 1-10.

GUILAINE J. (1985) - Le Néolithique ancien de la grotte des Fées à Leucate (Aude, France) et ses implications, in M. LIVERANI dir., Studi di Paletnologia in onore di Salvatore M. Puglisi, Roma, Université de Rome La Sapienza, p. 505-516.

GUILAINE J. (1986) - Le Néolithique ancien en Languedoc et Catalogne : éléments et réflexions pour un essai de périodisation, in J.-P. DEMOULE, J. GUILAINE dir., Le Néolithique de la France : hommage à Gérard Bailloud, Paris, Picard, p. 71-82.

GUILAINE J., VAQUER J., GASCO J., BARRIE P. (1980) - Le Néolithique récent-final et le Chalcolithique de l'abri de Font-Juvénal (Aude), in : J. GUILAINE dir., Le groupe de Véraza et la fin des temps néolithiques dans le sud de la France et la Catalogne, Colloque (Narbonne, 1977), Éd. du CNRS, Paris, p. 13-19.

GUILAINE J., FREISES A., MONTJARDIN R., BARBAZA M., COULAROU J., COURTIN J., et coll. (1984) - Leucate-Corrège : habitat noyé du Néolithique Cardial, Toulouse, Centre d'anthropologie des Sociétés rurales, École des Hautes Etudes en sciences sociales, Sète, Musée P. Valéry, 270 p.

GUTHERZ X., JALLOT L. (1995) - Le Néolithique final du Languedoc méditerranéen, in J.-L. VORUZ dir., Chronologies néolithiques : de 6000 à 2000 ans avant notre ère dans le Bassin rhodanien, Colloque (Ambérieu-en-Bugey, 19-20 sept. 1992), Ambérieu-en-Bugey, Soc. préhist. Rhodanienne, Doc. du Dép. d'anthrop. et d'écologie de l'Univ., 20, p. 231-263.

HELMER D. (1995) - Biometria i arqueozoologia a partir d'alguns exemples del Proxim Orient, Cotà Zero, 11, p. 51-60.

HELMER D. (2000) - Discrimination des genres Ovis et Capra à l'aide des prémolaires inférieures 3 et 4 et interprétation des âges d'abattage : l'exemple de Dikili tash (Grèce), in G. GIACOBINI, B. BASSANO dir., La gestion démographique des animaux à travers le temps Animal management and demography through the ages, $V I^{e}$ Colloque international de l'association "L'Homme et l'Animal, Société de Recherche Interdisciplinaire”, Turin, Italy, 16-18 September 1998, Ibex - Anthropozoologica, sous presse.

LESUR J., VIGNE J.-D. (en prép.) - Modalities of accumulation of microvertebrates into large Iron Age pits at d'Acy-Romance (Ardenne, France), Archaeofauna.

MANEN C. (2000a) - Le Néolithique ancien entre Rhône et Èbre : analyse des céramiques décorées, Toulouse, EHESS (Thèse de doctorat, non publiée), $398 \mathrm{p}$.

MANEN C. (2000b) - Implantation de faciès d'origine italienne au Néolithique ancien : l'exemple des sites "Liguriens" du Languedoc, in : Société et espace, III ${ }^{e s}$ Rencontres Méridionales de Préhistoire Récente (Toulouse, novembre 1998), Toulouse, Archive d'Écologie Préhistorique, p. 35-42.

MANEN C. (à paraître) - Émergence, développement et évolution du Néolithique ancien en Languedoc-Roussillon, in : Temps et espaces culturels, $I V^{\text {s }}$ Rencontres Méridionales de Préhistoire Récente (Nîmes, Octobre 2000).

MARINVAL P. (1988) - Cueillette, agriculture et alimentation végétale de l'Épipaléolithique jusqu'au $2^{e}$ Âge du Fer en France méridionale. Apports palethnographiques de la carpologie, Toulouse, EHESS (Thèse de doctorat, non publiée), $458 \mathrm{p}$. 
MARSAC P. (1990) - La fin du Néolithique et les débuts de la métallurgie en Languedoc occidental et Roussillon, Toulouse, EHESS (Thèse de doctorat, non publiée), $302 \mathrm{p}$.

MARTÍN COLLIGA A. (1992a) - Dinamica del Neolitico antiguo y medio en Cataluña, in P. UTRILLA MIRANDA dir., Aragon/Litoral mediterraneo : intercambos culturales durante la Prehistoria, Colloque (Zaragoza, 1988), p. 319-333.

MARTIN COLLIGA A. (1992b) - Estrategia y culturas del Neolitico final y Calcolitico en Cataluna, in P. UTRILLA MIRANDA dir., Aragon/Litoral mediterraneo : intercambos culturales durante la Prehistoria, Colloque (Zaragoza, 1988), p. 389-397.

MARTIN COLLIGA A., VAQUER J. (1995) - El poblament dels pirineus a l'Holocè, del Mesolític a l'Edat del Bronze, in J. BERTRANDPETIT, E. VIVES, dir., Muntanyes i Població. El passat dels Pirineus des d'una perspectiva multidisciplinària, Andorra La Vella, Centre de Trobada de les Cultures Pirinenques, p. 35-72.

MARTIN COLLIGA A., VILLALBA IBAÑEZ M.J. (1999) - Le Néolithique moyen de la Catalogne, in J. VAQUER dir., Le Néolithique du Nord-Ouest méditerranéen, Congrès préhistorique de France, XXIV, Caracassonne, septembre 1994, Joué-lès-Tours, Société Préhistorique Française, p. 211-224.

MARTZLUFF M., ABELANET J. (1987) - La Cova de l'Esperit : bilan des dernières recherches et nouveaux apports sur le Mésolithique et le Néolithique des Pyrénées-Orientales, in : Études roussillonnaises offertes à Pierre Ponsich, Perpignan, Centre d'Études Préhistoriques Catalanes, Travaux de Préhistoire roussillonnaises, 4, p. $99-113$

MARTZLUFF M., PASSARIUS O., VIGNAUD A., DONÈS C. (1995) Nouvelles données sur le Néolithique ancien du Roussillon, Études roussillonnaises, XIII, p. 7-16.

MEADOW R.H. (1999) - The use of size index scaling techniques for research on archaeozoological collections from the Middle East, in C. BECKER, H. MANHART, J. PETERS, J. SCHIBLER dir., Historia animalium ex ossibus, Festschrift für Angela von den Driesch, Rahden, Westf., Leidorf, p. 285-300.

PAYNE S. (1969) - A metrical distinction between sheep and goat metacarpals, in : P.J. UCKO, G.W. DIMBLEBY dir., The domestication and exploitation of plants and animals, G. Duckworth \& $\mathrm{Co}$, Londres, p. 295-305

PAYNE S. (1973) - Kill-off patterns in sheep and goats : the mandibles from Asvan Kale, Anatolian studies, 23, p. 281-303.

PAYNE S. (1985) - Morphological distinction between the mandibular teeth of young sheep (Ovis) and goat (Capra), Journal of Archaeological Science, 12, p. 139-147.

RODRIGUEZ G. (1968) - Le Néolithique dans le Saint-Ponais (Hérault), Bulletin de la Société préhistorique française, t. 65, 3, p. 699-749.

RODRIGUEZ G. (1984) - La grotte de Camprafaud : contribution à l'étude du Néolithique en Languedoc central, Montpellier, Office régional de la culture du Languedoc-Roussillon, $417 \mathrm{p}$.

ROUDIL J.-L., EVESQUE R., DA SILVA J. (1991) - L'abri de la Tardive. Berrias - Casteljau (Ardèche), Ardèche Archéologie, 8, p. 19-28.

SALANOVA L. (2000) - La question du Campaniforme en France et dans les îles anglo-normandes. Productions, chronologie et rôles d'un standard céramique, Paris, Éd. du CTHS, Société préhistorique française, 2000, Documents préhistoriques, 13, $391 \mathrm{p}$.

SAÑA I SEGUI M. (1993) - Estudi de les relacions entre grup humamón animal. Dinàmica del procès de domestocació animal al Neolític antic català. L'exemple de La Draga (Banyoles-Pla de l'Estany), Barcelone, Université Autonome (Diplôme, non publié).

SAVARD M. (2000) - Étude de l'assemblage carpologique de la baume de Fontbrégoua (Var) du Paléolithique final au Chasséen récent, Paris, Université de Paris I, (Mémoire de DEA, non publié), 60 p.

TARRÚS J., CHINCHILLA J., BUXÓ R., SANA M. (1992) - La Draga (Banyoles) un hàbitat lacustre del Neolitic antic, in $\mathrm{M}$.
CURA-MORERA dir., Estat actual de la investigaciò sobre el Neolitic a Catalunya, Colloqui internacional d'arqueologia, 9 (Puigcerdà, 1991) : centenari del naixement de P. Bosch Gimpera, Puigcerdà i Andorra, Institut d'estudis Ceretans, p. 89-92.

TARRÚS J., CHINCHILlA J., BOSCH À. (1994) - La Draga (Banyoles) : un site lacustre du Néolithique ancien cardial en Catalogne, Bulletin de la Société préhistorique française, t. 91, 6, p. $449-456$.

TASCA G. (1998) - Intonaci e concotti nella preistoria : tecniche di rilevamento e problemi interpretativi, in: Introduzione all'archeologia degli spazi domestici, Atti del seminario, Como 4-5 nov., Como, Edizioni New Press, Archeologia dell'Italia Settentrionale, 7, p. 77-87.

TREINEN-CLAUSTRE F. (1982) - Un gisement du Néolithique final dans le Fenouilledes. La grotte de Chincholle à Camps-sur-Agly (Aude), Bulletin de la Société scientifique de l'Aude, LXXXII, p. 7-16.

TRESSET A., VIGNE J.-D. (2000) - La chasse, principal élément structurant la diversité des faunes archéologiques du Néolithique ancien, en Europe tempérée comme en Méditerranéenne : tentative d'interprétation fonctionnelle, in R.-M. ARBOGAST, C. JEUNESSE, J. SCHIBLER dir., Rôle et statut de la chasse dans le Néolithique ancien danubien (5500-4900 av. J.-C.), Actes Premières rencontres danubiennes de Strasbourg, 20-21 nov. 96, sous presse.

TRESSET A., VIGNE J.-D. (sous presse) - Le dépôt d'animaux de la structure e4 d'Er Grah : une illustration de la symbolique des bovins à la charnière du Mésolithique et du Néolithique bretons ? in C.-T. LE ROUX dir., Locmariaquer, Er Grah, Paris, Document Archéologie Française.

VAQUER J. (1980) - Le groupe de Véraza. Essai sur l'évolution de la culture matérielle, in J. GUILAINE dir., Le groupe de Véraza et la fin des temps néolithiques dans le sud de la France et la Catalogne, Colloque (Narbonne, 1977), Éd. du CNRS, Paris, p. 84-93.

VAQUER J. (1986) - Les débris de structures et les éléments modelés en torchis et pisé, in : Carsac. Une agglomération protohistorique en Languedoc, Toulouse, Centre d'anthropologie des sociétés rurales, p. $183-187$

VAQUER J. (1998) - Le Midi méditerranéen de la France, in : Atlas du Néolithique européen. L'Europe occidentale, Liège, Service de préhist. de l'Univ. (Études et rech. archéol. de l'Univ. de Liège, 46), p. 413-500.

VIGNAUD A. (1990) - Nouvelles données sur l'implantation d'habitats néolithiques de plein air en Vallespir, Travaux de Préhistoire catalane, 6, p. 103-115.

VIGNAUD A. (1992) - Nouvelles données sur les gisements de plein-air néolithiques dans le Bassin du Tech et de l'Agly, dans les Pyrénées orientales, in: Estat de la investigacio sobre el Neolitic a Catalunya. Colloqui internacional d'arqueologia, 9 (Puigcerdà, 1991) : centenari del naixement de P. Bosch Gimpera, Puigcerdà i Andorra : Institut d'estudis Ceretans, p. 170-171.

VIGNE J.-D. et al. (1986) - Le milieu animal : la faune du site de Carsac, in: Carsac. Une agglomération protohistorique en Languedoc, Toulouse, Centre d'anthropologie des sociétés rurales, p. 219-254.

VIGNE J.-D. (1988) - Les Mammifères post-glaciaires de Corse, étude archéozoologique, $\mathrm{XXVI}^{\mathrm{e}}$ suppl. à Gallia Préhistoire, Paris, CNRS, $337 \mathrm{p}$.

VIGNE J.-D. (1996) - La faune de Vertébrés, in J. GASCÓ et al. dir. Le Laouret et la montagne d'Alaric à la fin de l'Âge du Bronze, Toulouse, Centre d'Anthropologie, EHESS-CNRS, p. 197-239.

VIGNE J.-D. (1998) - Faciès culturels et sous-système technique de l'acquisition des ressources animales. Application au Néolithique ancien méditerranéen, in : A. D'ANNA, D. BINDER dir., Production et identité culturelle. Actualité de la recherche, Actes $2^{\text {es }}$ Rencontres méridionales de Préhistoire récente, Arles, 8-9 nov. 1996. Antibes, APDCA, p. 27-45.

VIGNE J.-D., HELMER D. (1999) - Nouvelles analyses sur les débuts de l'élevage dans le Centre et l'Ouest méditerranéens, in J. VAQUER 
dir., Le Néolithique du Nord-Ouest méditerranéen, Congrès préhistorique de France, XXIV (Caracassonne, septembre 1994), Joué-lèsTours, Société Préhistorique Française, p. 129-146.

Claire MANEN,

Denis LOIRAT,

Laurent BOUBY

VIGNE J.-D., BAILON S., VALLET C. (1994a) - Les microvertébrés terrestres de Sierentz-Landstrasse (Haut-Rhin, La Tène finale au III ${ }^{c}$ s. ap. J.-C.), Cahiers pour la Promotion de la Recherche archéologique en Alsace, 10, p. 68-96.

UMR 8555, Centre d'Anthropologie 39, allées Jules-Guesde, 31000 Toulouse

VIĞNE J.-D., MENIEL P., LAMBOT B., BONANI G. (1994b) - Un assemblage d'ossements de micromammifères dans une cache de mustélidé de l'Âge du Fer (Acy-Romance, Ardennes, France), in M PATOU-MATHIS dir., Outillage peu élaboré en os et en bois de cervidés, IV, Taphonomie, Artefact, 9, p. 207-215.

Jean-Denis VIGNE

ESA 8045 - CNRS

Muséum national d'Histoire naturelle Laboratoire d'Anatomie comparée 55 , rue Buffon 75005 Paris 